\title{
Generalized nets and intuitionistic fuzziness as tools for modelling of data mining processes and tools
}

\author{
Krassimir Atanassov ${ }^{1,2}$ \\ ${ }^{1}$ Department of Bioinformatics and Mathematical Modelling, \\ Institute of Biophysics and Biomedical Engineering \\ Bulgarian Academy of Sciences \\ Acad. G. Bonchev Str., B1. 105, Sofia-1113, Bulgaria, \\ ${ }^{2}$ Prof. Asen Zlatarov University, Bourgas-8000, Bulgaria \\ e-mail: kratebas.bg
}

Received: 6 June 2020

Revised: 1 October 2020

Accepted: 15 November 2020

\begin{abstract}
The possibilities for using the apparatuses of generalized nets and intuitionistic fuzzy sets as means for modelling and evaluation of Data Mining processes and tools are discussed and illustrated by examples.
\end{abstract}

Keywords: Data Mining, Generalized net, Intuitionistic fuzzy set.

2010 Mathematics Subject Classification: 03E72, 68Q85.

\section{Introduction}

Here, following and extending [26,31], we discuss the origin, the current state of research and the applications of Generalized Nets (GNs) and Intuitionistic Fuzzy (IF) tools in the area of Data Mining (DM) .

First, following [26,31], we give a short list of the different areas which various authors consider to lay at the foundation of the Artificial Intelligence (AI) framework:

(a) different kinds of automatic theorem proving;

(b) methods for finding of paths in labyrinths; 
(c) intellectual games;

(d) pattern recognition;

(e) scene analysis;

(f) natural languages and semantic networks;

(g) robotics;

(h) expert systems;

(i) (artificial) neural networks;

(j) genetic algorithms;

(k) computer learning;

(I) Turing machines and different types of finite automata;

(m) planning systems;

(n) multi-agent systems;

(o) heuristics based problems related to scheduling, assignment, optimization, decision making, etc.;

(p) LISP, PROLOG, and their modifications;

and others.

Of course, this classification is not complete. In addition, it is outdated - it was prepared in 1991, when the author formulated the hypothesis that if there exists a unique mathematical tool that can describe all areas of AI, then this area of knowledge will be essentially developed. My thesis from 1991 was that the apparatus of GNs is such a tool.

Now, the author is prone to think that Data Mining - as an essentially new area of sciences - can be interpreted as a natural extension and union of some of the areas of AI. Therefore, we discuss how to represent each of the above areas in terms of GNs and also how both sides (AI and GN theory) will benefit from that. As far as the latter is concerned, imagine a mathematical tool that can play the role of a relatively universal language for describing all scientific areas listed above, and even more. Moreover, we will see that the individual areas of AI have a common background, although at the moment it is not clear whether it is true for all or only for a part of them. Therefore, this will facilitate the transfer of ideas from one area to another, as well as their stronger formalization and further development.

There exists, however, another problem - how to generalize and extend this description, within the framework of the GN-description of each event, adding new (perhaps not yet existing but theoretically possible) elements in a way that allows the newly obtained process (object) to be described by a GN, as well. If we can achieve this, then it will be clear that GNs are not only capable of describing processes (objects), but they serve to construct new, even not yet existing, processes (objects).

Finally, a third problem arises, namely to search for the possible directions of further development of GN-methodology and new objects to be described by it. 
Simultaneously, we will discuss the possibility to use the IF-tools for evaluation of DM procedures and objects.

Now, we shortly discuss the already existing results. They are collected in the books $[31,43$, $54,56,100,123,170,177,189,249,258,259,272]$, which are based on a lot of papers in journals and conference proceedings.

In book [31], nine GN-models of Expert Systems (ESs) are described. In [42], we will discuss the results from this book in more detail, because some ideas from there can be transferred directly for the DM case. A continuation of these ideas is given in $[100,170]$, where the functioning and the results of the work of relational databases, uncertain data and knowledge engineering processes are described by GNs.

The book [43] contains GN-models of process of machine learning of: neural networks, genetic algorithms, intellectual games, GNs and intuitionistic fuzzy GNs, abstract systems, and others. The process of machine learning described by a GN essentially extends the standard machine learning process, but we can now also take into account many facts generated at the time of the GN-functioning which are related to the training process, as well as to the object of learning.

The processes of pattern recognition and decision making are represented by GN-models in books [54,56]. Multi-criteria decision making procedures are described by GNs in [64,215,216], while the procedures of intercriteria analysis (see $[60,78,80]$ ) are described by GNs in future author's book [42].

The GN-models of a part of the existing types of Neural Networks (NN) are described in books $[177,189,272]$ and in papers $[1,8,12,13,59,68-70,112,136,140,178-186,188-190,197$, 205, 227, 228, 266-271, 273-282, 284-288, 292].

In book [123], the Ant Colony Optimization procedures, introduced by M. Dorigo [113, 114] are described by GNs, while in book [249] and papers [66,219-225, 241-243,245-248,250,251], the functioning and the results of the work of different types of genetic algorithms are represented by GNs.

Existing research shows that there is a possibility for GNs to be used as tools for modelling of practically all AI paradigms.

\section{Generalized nets and Data Mining - possibilities for the future}

What is Data Mining? The answer of this question is so unclear, as well as the answer of the question for the areas of AI. Again, there are different answers with respect to the opinions of the specialists, giving answers. For example:

"The aim of DM is to make sense of large amounts of mostly unsupervised data, in some domain" [106];

"The aim of DM is to extract implicit, previously unknown and potentially useful (or actionable) patterns from data. DM consists of many up-to-date techniques such as classification (decision trees, naive Bayes classifier, $k$-nearest neighbor, NNs), clustering ( $k$-means, hierar- 
chical clustering, density-based clustering), association (one-dimensional, multi-dimensional, multilevel association, constraint-based association)" [300];

"DM stands at the confluence of the fields of statistics and machine learning" [263];

"DM is a tool, not a magic wand" [161];

"DM is a term that covers a broad range of techniques being used in a variety of industries" [252];

"DM is the core of the knowledge discovery in databases process, involving the inferring of algorithms that explore the data, develop the model and discover previously unknown patterns" [193].

Data Mining is a process of finding reasonable correlations, repeating patterns and trends in large DBs. There are a lot of papers and books, devoted to DM. As a basis of our research, we use the publications $[11,83,84,86-88,99,105,106,108,110,138,141,143,151-158,161,166-$ $169,193,199,213,217,218,230,234,239,252,257,263,293,300,309,310,312]$.

Extending the text from [31], here we make a review of some of the problems related to the above ones - those already existing, and those planned for future research within the framework of the theory of GNs. Everywhere we emphasize on:

- the way GNs have been used to describe the process (object) up to now (if ever);

- possible extensions or generalizations of already existing GN-models of the corresponding processes (objects) and ways for their modifications;

- possibilities for construction of new GN-models.

\section{Expert systems, databases, data warehouses, big data and OLAP-structures}

A lot of colleagues already assert that the ESs are dying. The author supports the idea that they will live their "Renaissance", obtaining a special place in the instrumentation of DM. Preserving their basic purpose to generate new knowledge by answering hypotheses, we can essentially extend the area of their capabilities. When some unclear situation arises in a process controlled by DM-tools, and when some hypotheses for its future development are generated, then the new type of ESs can help.

In a series of papers collected in [31], the author described the basic steps of the process of the functioning and the results of work of ESs.

The first of the models from [31] shows how a GN-model of a given ES can be constructed. This model contains information about the separate ES components (Data Base (DB), Knowledge Base (KB) hypotheses), which are represented by GN-transitions, places, tokens and token characteristics. It shows that we can construct one GN-model for any ES. In the second and third GN-models from [31], a part of the GN-components that correspond to the ES-components are changed only by token characteristics. In the second GN-model the DB is represented by a characteristic of a specially constructed token, while in the third GN-model the same is done for the KB. 
Therefore, the second and the third GN-models are already independent of the concrete DB and the concrete KB of a given ES, being modelled by the GN. Hence, the third GN-model is universal for the class of all ordinary ESs.

The fourth GN-model is an extension of the third one, but with the possibility to represent $\mathrm{KB}$ rules containing the operation "negation" in their antecedents. The remaining five GN-models, described in [31], are devoted to extensions of the concept of an ES. The new ESs contain new components, which can be represented by the GN-tools. Of course, these new components are not all of those necessary for modelling concrete expert processes, but they illustrate the possibility for extending the ES-structures, and in separate cases they can be useful.

The fifth GN-model represents the functioning and the results of the work of an ES, with priorities of the data within its DB. The data have now a specific priority. At the time of the ES functioning (within the context of a GN-model), new data (represented by GN-tokens) can enter the DB changing the existing information in it (if the new data are in contradiction with the data already existing, and if the priority of the new data is greater than the priority of the old), or confirm it. There are special tools, described by GN-subnets, which can check the correctness of the new data and this information will enter the DB only if it is not in contradiction with the existing rules of the ES's $\mathrm{KB}$.

The seventh GN-model is devoted to an analogous extension of the ES, but now related to its $\mathrm{KB}$. The rules there have priorities and they can be changed or confirmed as in the previous case. Now, there are GN-subnets that check the correctness of the new rules and they will enter the DB only if they are not in contradiction with the existing rules of the ES's KB and with the existing data in the ES's DB.

The sixth GN describes an ES that contains "metafacts". This new concept is similar to DB facts and simultaneously to the KB rules. In practice, the metafacts can be interpreted as facts about the DB-facts, as well as, as simple KB-rules.

The concept of an Intuitionistic Fuzzy ES (IFES) was introduced in [28] as an extension of fuzzy ESs. The estimations of the truth-values of the facts there have the form $\langle m, n\rangle$, where $m, n \in[0,1]$ and $m+n \leq 1$. Numbers $m$ and $n$ correspond to the degree of validity and the degree of non-validity of the fact. In this case, there possibly exists a degree of uncertainty $p$, for which $p=1-m-n \geq 0$. The three components of the Intuitionistic Fuzzy Set (IFS) [32,37] and its derivatives (intuitionistic fuzzy logics, intuitionistic fuzzy graphs, intuitionistic fuzzy abstract systems, intuitionistic fuzzy ESs, and so on), give greater possibilities for the real processes modelling than ordinary fuzzy objects. The eighth GN-model describes the functioning and the results of the work of an IFES.

On the basis of the modal types of operators defined over IFSs, the eighth GN-model was constructed so that it represents the functioning and the results of an ES using modal logic operations.

Here, we must mention that in [28], the concept of an Intuitionistic Fuzzy ES (IFES) was introduced. It was essentially extended in $[31,100,103,170]$. In these ESs, each fact $F$ has IFestimations $\langle\mu(F), \nu(F)\rangle$, determining its degrees of validity and non-validity. So, the answer whether a given hypothesis is valid or not, obtains essentially more exact evaluation. In near future, we will introduce an extension of the IFES whose facts will have the IVIF-estimations 
$\langle M(F), N(F)\rangle$, where $M(F), N(F) \subseteq[0,1]$ and $\sup M(x)+\sup N(x) \leq 1$. So, we will define Interval Valued IFES (IVIFES). A next step of the extensions will be introducing of facts that contain moments of time, when they started to be valid, and moments in which they ceased being valid (a sequence of time-moments $t_{1}, t_{2}, \ldots, t_{n}$ ). Then (cf. [31]), on the one hand we can answer to questions related to the time ("at the moment", "once", "sometimes", "for long/short time", "often", "rarely", "for short period", "for long period", etc. ). On the other hand, the IVIFES rules can have essentially complex forms, containing different logical operations (conjunction, disjunction, implication, negation, ...), quantifiers ("exists" and "for all") and modal operators in their antecedents. In addition, the facts and rules can have priorities that will determine whether a given fact or rule can stay in the DB or must be changed with another one.

Finally, the ninth GN-model, described in [31], represents the functioning and the results of the work of an ES with rules, related to a fixed time-scale, which is given as characteristics of a special GN-token. In this way, we can construct a temporal ES using temporal logic operators.

A continuation of these ideas is given in $[100,170]$, where the functioning and the results of the work of relation databases, uncertain data and knowledge engineering processes are described by GNs.

The OLAP-structures (see, e.g. [106]) can be well represented by the means of IMs [9698, 301, 302] and especially by multi-dimensional IMs. IMs were developed as tools for formal mathematical description of the GN-transitions and logic of the modelled process. On the other hand, it is easily seen that the processes of realization of the operations, relations and operators over IMs can be described by GNs. So, GNs can be used as a tool for description of the operations in OLAP-structures [101, 102].

In [194-196] GN-models and IF-estimations of pipelined, cloud computing and others are discussed.

\section{Heuristics-based pattern and speech recognition, scene analysis, planning systems, scheduling related problems, assignment, optimization, decision making, etc.}

Books $[54,56]$ contain GN-models in the areas of pattern and speech recognition, describing the processes of face, signature, handwriting and typewriting texts recognition. On this basis, the processes of decision making for obtaining classified access are represented by GNs. The most interesting in this case is the possibility for automatic generation of checks for the individuals who do not satisfy all but just a part of the access conditions. In this case, the control tool determines other checks (for which information exists in the respective DBs) and preserves/stores the changes in the information about the individuals who should obtain access. So, the next time, these individuals are checked against the new and older data existing for them. A GN-model describing this process will be given in the book [42]. It is an extension of the previous models on this theme.

In the areas of planning systems, problems related to scheduling, assignment and others based on heuristics, there are only a few attempts to model processes by GNs. At the moment, the 
existing research in the above areas is related to the problems of the decision making [54,215, 216], the travelling salesman [22, 25, 27] and to the transportation problem [24]. For the last problem it has been shown that on one hand the process of its solution can be described by a GN.

After constructing a GN for the movement of one travelling salesman, the constructed GN was extended. Its transition condition predicates and its tokens' characteristic functions were modified, and the new GN is capable of describing the following problem: determine the best move of each of a fixed set of travelling salesmen, collected in $n$ groups, if:

- every two salesmen, from different groups compete;

- for each travelling salesman, the types of the products which he sells, are known in advance;

- for each product of a given salesman, its price, its quantity, the date of its production and its expiry date are known (i.e., a part of the salesman production may be discarded);

- for each graph vertex, the necessary quantity of different types of products is known;

- for each two adjacent vertices, the distances between them, the cost of the path and the possibility for connection between them at a given time-moment are known.

The following question is very interesting (and its answer can be obtained within the frames of a corresponding GN-model): Can a GN-model, similar to the above one, be constructed so that the "travelling salesmen" search for concrete information in a DB or a Data Warehouse $(D W)$ ? Now, the "salesmen" will collect information instead of selling things and the attributes of this information (quality, quantity, time-moments (or periods) of validity, etc.) correspond to product attributes. Since the behaviour of the "salesmen" is similar to the agents from multiagents systems (see, e.g. $[107,145]$ ), below, we denote the objects from the "salesmen"-type as "agents".

Some GN-models of decision making processes are given in book [54] and in papers [215, 216].They can find applications as solutions of decision-making agents that must collect suitable information from a $\mathrm{DB} / \mathrm{DW} / \mathrm{KB}$ and to represent it in a predefined form. In the book [42], we describe a new GN-model of decision making processes.

Another important question is related to the development of algorithms for automatic learning of the already constructed GN-models.

In [174-176], it is shown that the basic UML-components can be represented by GNs.

The apparatus of the IFLs is suitable for estimation of different pattern recognition procedures. Some of them, but in a combination with the concept of a GN are described in [54]. Here, we give the following short example. Let us have some original pattern - in our example, triangle $A B C$ that must be compared to other pattern - e.g., triangle $A D E$ (see Fig. 1). 


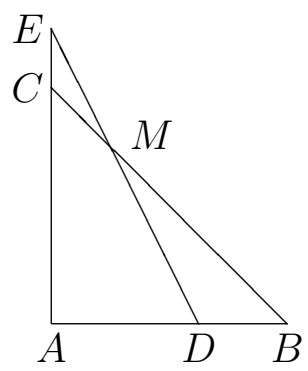

Figure 1.

Let $a$ be the surface of the region $A B M E$ that includes both triangles, $b$ be the surface of the region $A D M C$ that is included in both triangles and let $c$ and $d$ be the surfaces of triangles $D B M$ and $C E M$, respectively. Therefore, the IF-degree of coincidence of second pattern with the original pattern will be $\left\langle\frac{b}{a}, \frac{c}{a}\right\rangle$, i.e., the degree of coincidence is $\frac{b}{a}$, the degree of non-coincidence is $\frac{c}{a}$ and the degree of uncertainty is $\frac{d}{a}=1-\frac{b}{a}-\frac{c}{a}$. This simple example shows the IF-possibility to estimate more detail than the fuzzy set tools, because in the fuzzy set-case, the estimation had to be only $\frac{b}{a}$.

\section{Process of natural language analysis, semantic networks and translation}

At the moment, there exist only two attempts for research in this direction and they are related to the GN-description of semantic networks in [203] and of a translation process in [53]. After the first step, the question arises about extending the semantic networks in the direction of, for instance, their (intuitionistic) fuzziness and the representation of the new nets by GNs. In future, there will be constructed GNs, which describe the translation process of information from a DB/DW from one language to another.

\section{Clusterization and classification of data, processes of rule extraction, of solution/decision-tree generation and of associative rule construction}

The first attempts of GN models of clusterisation and classification procedures are discussed in [89,91-95], but until now none of the processes of rule extraction, of solution-tree generation and of associative rule construction exist. It will be important that in future GN-models for all these procedures and processes are developed. For example, it will be interesting to construct a GN that contains as subnets the GNs that describe the functioning and the results of the work of the separate clusterization procedures.

The first attempts to use IF-estimations in clusterization and classification of data are described in $[37,90]$ with the introduction of the concept of an IF histogram, but for the moment none of the processes of clusterisation, classification, rule extraction, decision-tree generation and 
associative rule construction, has made use of IF-estimations. In future, it will be important to develop procedures for determining IF-estimations for all these particular procedures and processes. The IF-operations and operators will give us the possibility to determite pessimistic, optimistic, standard and other IF-estimations.

\section{Knowledge discovery processes and processes for imputation of missing data}

"The Knowledge Discovery Process (KDP), also called knowledge discovery in databases, seeks new knowledge in some application domain. It is defined as the nontrivial process of identifying valid, novel, potentially useful, and ultimately understandable patterns in data." [106]. In the same book, two missing data imputation methods, the mean and the hot deck, are described. Both types of processes can be described by GNs and this will be an aim of the author for the future and can be evaluated by IF-estimations and as a result, more detailed information for them is expected to be obtained.

\section{Neural networks and evolutionary algorithms}

The idea for Intuitionistic Fuzzy Neural Networks (IFNNs) was introduced in [146-150] about 30 years ago. It was discussed in the books $[189,272]$. In a series of papers, functioning and the results of the work of different types of neural networks are described $[1,13,59,68-70,112,136$, 140, 177-180, 182, 184, 186, 188, 190, 197, 205, 227, 228, 266-271, 273-281, 283-287, 298].

\section{Procedure for inductive reasoning}

As is mentioned in [143], "the rule induction is one of the fundamental tools of DM. Usually rules are expressions of the form

$$
\begin{gathered}
\text { if }\left(\text { attribute }_{1}, \text { value }_{1}\right) \&\left(\text { attribute }_{2}, \text { value }_{2}\right) \& \ldots \&\left(\text { attribute }_{n}, \text { value }_{n}\right) \\
\text { then (decision, value }) .
\end{gathered}
$$

Obviously, the process of evaluation of the truth values of the members of the antecedent can be represented by the sequential characteristic of a fixed token in the GN and when it has obtained all $n$ characteristics, it will obtain in addition the characteristic "(decision, value)".

Therefore, the discussed procedure is representable by GNs. But now, we can use, e.g., an intuitionistic fuzzy GN from the third type. In this case, we obtain sequentially the following $n$ characteristics 


$$
\begin{gathered}
\left(\text { attribute }_{1}, \text { value }_{1}, \mu_{1}, \nu_{1}\right), \\
\left(\text { attribute }_{2}, \text { value }_{2}, \mu_{2}, \nu_{2}\right), \\
\ldots \\
\text { (attribute } \left._{n}, \text { value }_{n}, \mu_{n}, \nu_{n}\right),
\end{gathered}
$$

where, in the simplest case

$$
\mu_{i}= \begin{cases}1, & \text { if } \text { value }_{i} \text { is anticipated (expected, correct, etc.) } \\ 0, & \text { if } \text { value }_{i} \text { is not anticipated (not expected, incorrect, etc.) } \\ *, & \text { if there is no information for attribute }\end{cases}
$$

and $\nu_{i}=1-\mu_{i}$, but in more general case $\mu_{i}, \nu_{i} \in[0,1]$ and $\mu_{i}+\nu_{i} \leq 1$. The $(n+1)$-th characteristic can have the form

$$
\text { (decision, value, } \mu, \nu)
$$

where

$$
\mu=\frac{p}{n}, \quad \nu=\frac{q}{n}
$$

and $p$ is the number of degrees $\mu_{i}$ that are equal to $1, q$ is the number of degrees $\nu_{i}$ that are equal to 1. Obviously, $p+q \leq n$. Therefore, the evaluation $\langle\mu, \nu\rangle$ is an intuitionistic fuzzy pair. Hence, we obtain more precise estimation for the validity of the procedure for inductive reasoning. If in the beginning we determine some threshold of validity $t_{v}$, then we can assert that a decision is sufficiently valid if $\mu>t_{v}$. On the other hand, if we determine some threshold of non-validity $t_{n}$ then we can assert that a decision is sufficiently valid if $\nu<t_{n}$.

If we use the IVIF-apparatus, the final estimation can have the form

$$
\text { (decision, value, } M, N) \text {, }
$$

where $M, N \subseteq[0,1]$ and $\sup M+\sup N \leq 1$, and

Let $p$ be the number of degrees $\mu_{i}$ that are equal to $1, q$ be the number of degrees $\nu_{i}$ that are equal to $1, r$ be the number of degrees $\mu_{i}$ that satisfy $1>\mu_{i}>\frac{1}{2}, s$ be the number of degrees $\nu_{i}$ that satisfy $1>\nu_{i}>\frac{1}{2}$. Obviously, $p+q+r+s \leq n$.

Now, the final estimation can have the IVIF-form

$$
\text { (decision, value, } M, N) \text {, }
$$

where

$$
\begin{aligned}
M & =\left[\frac{p}{n}, \frac{p+r}{n}\right], \\
N & =\left[\frac{q}{n}, \frac{q+s}{n}\right] .
\end{aligned}
$$

Therefore, $M, N \subseteq[0,1]$ and $\sup M+\sup N \leq 1$. 
Repeating the above words for the IF-case, now we will say that we obtain more precise estimation for the validity of the procedure for inductive reasoning than in the cases of standard, fuzzy and intuitionistic fuzzy inductive reasoning. If in the beginning we determine some threshold of validity $t_{v}$, then we can assert that a decision is positive sufficiently valid, if $\sup M>t_{v}$ and it is strongly positive sufficiently valid, if inf $M>t_{v}$. On the other hand, if we determine some threshold of non-validity $t_{n}$ then we can assert that a decision is negative sufficiently valid, if inf $N<t_{n}$ and it is is strongly negative sufficiently valid, if $\sup N<t_{n}$.

The procedures for decision making include the multi-criteria decision making procedures that can be re-organized so that they use IVIF-estimations. For example, let us have $s$ experts who must estimate some objects or processes. Let $m$ of them estimate it as "perfect", "the best" or "very good"; $n$ of them - as "worst" or "very bad"; $r$ - as "good", "suitable" or "useful"; and $s$ - as "bad", "non-suitable" or "non-useful", then we can estimate the objects or processes by IVIF-estimations.

In [39], a new type of decision making procedure, based on the apparatus of the intercriteria analysis, is discussed. It is called intercriterial decision making. Its aim is to search dependencies among the used criteria. For example, it is very suitable when separate experts offer for use in concrete procedure different criteria. Now, after finishing of the procedure, we can determine whether there are connections between some of these criteria. In IFS-case, this procedure is discussed in [75], while for the IVIFS-case similar research has appeared. The new method is based on the apparatus of the IMs.

\section{Statistical procedures for Data Mining}

Up to now, there have been no GN-models of the statistical procedures for Data Mining, but their development can be realized in terms of GNs. Indeed, in some subset of a given GN-model of a real process we can collect the necessary information in the form of characteristics of especially determined GN-tokens. Other GN-tokens will collect the results of the statistical data processing. So, all statistical methods can obtain GN-realizations.

On the other hand, the IFSs give possibility for constructing of new statistical tools. For example, in [37], an following idea for IF-Histogram (IFH) is described and two illustrative examples are discussed.

Example 1. Let us take a sudoku puzzle that was being solved, no matter correctly or not, and let some of its cells be still vacant. For instance, the sudoku puzzle in Fig. 2 contains a lot of mistakes and is not complete, but it serves us well as an illustration.

Let us divide the $9 \times 9$ grid into nine $3 \times 3$ sub-grids, and let us arrange vertically these sub-grids one over another (see Fig. 3). Let the rows and columns of each sub-grid be denoted by " $i$ " and " $j$ ", and let each of the 9 cells in a sub-grid be denoted by the pair " $(i, j)$ ", where $i, j=1,2,3$. Let us design the following table from Fig. 4 , in which over the " $(i, j)$ " indices, that correspond to a cell, nine fields be placed, coloured respectively in white if the digit in the cell is even; black - if the digit is odd; and half-white half-black if no digit has been entered in the cell.

Now let us rearrange the table fields in a way that the black ones are shifted to the bottom 
positions, the black-and-white cells are placed in the middle and the white fields float to top. Thus, we obtain Fig. 5.

This new table has the appearance of a histogram and we can juxtapose to its columns the pair of real numbers $\left\langle\frac{p}{9}, \frac{q}{9}\right\rangle$, where $p$ and $q$ are respectively the numbers of the white and the black sudoku cells, while $9-p-q$ is the number of the empty cells. Let us call this object an intuitionistic fuzzy histogram. It gives us an idea of the kinds of numbers in the sudoku placeholders, and is clearer than the one we would have if we used a standard histogram. Back to the example from Fig. 5, the values of the individual columns will be, respectively: $\left\langle\frac{3}{9}, \frac{3}{9}\right\rangle,\left\langle\frac{3}{9}, \frac{4}{9}\right\rangle$, $\left\langle\frac{4}{9}, \frac{3}{9}\right\rangle,\left\langle\frac{5}{9}, \frac{4}{9}\right\rangle,\langle 1,0\rangle,\left\langle\frac{4}{9}, \frac{2}{9}\right\rangle,\left\langle\frac{4}{9}, \frac{4}{9}\right\rangle,\left\langle\frac{5}{9}, \frac{4}{9}\right\rangle,\left\langle\frac{1}{9}, \frac{4}{9}\right\rangle$.

\begin{tabular}{|l|l|l|l|l|l|l|l|l|}
\hline 6 & 1 & & 8 & 3 & & 5 & 4 & 2 \\
\hline 4 & 7 & 9 & 2 & 1 & & 6 & 3 & \\
\hline 3 & 1 & 5 & & 9 & & & 2 & 7 \\
\hline 1 & 9 & & 6 & 3 & & & 8 & 6 \\
\hline 7 & 5 & & 3 & 7 & 9 & 2 & 1 & 5 \\
\hline 2 & 6 & 3 & 1 & & 5 & 4 & & 9 \\
\hline 9 & 8 & 7 & 4 & 2 & 8 & 3 & 9 & 1 \\
\hline 5 & 3 & & 7 & 9 & 3 & 1 & 5 & \\
\hline 1 & 2 & 4 & 3 & 5 & 6 & & 7 & \\
\hline
\end{tabular}

Figure 2.

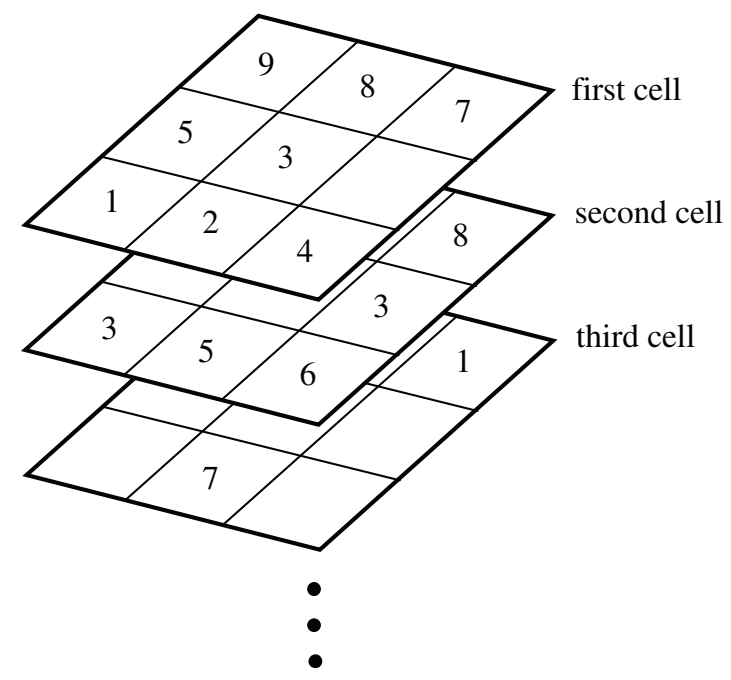

Figure 3. 
In the case of IFH, several situations may possibly rise:

1. The black-and-white cells count as white cells. Then we obtain the histogram on Fig. 6. We call it "N-histogram" by analogy with the modal operator "necessity" from $[32,37]$.

2. The black-and-white cells will be counted as half cells each, so that two mixed cells yield one black and one white cell. Then we obtain the histogram from Fig. 7. We call this histogram "A-histogram", meaning that its values are average with respect to Fig. 5.

3. The black-and-white cells count for black cells. Then we obtain the histogram from Fig. 8. This histogram will be called "P-histogram" by analogy with the modal operator "possibility" from $[32,37]$.

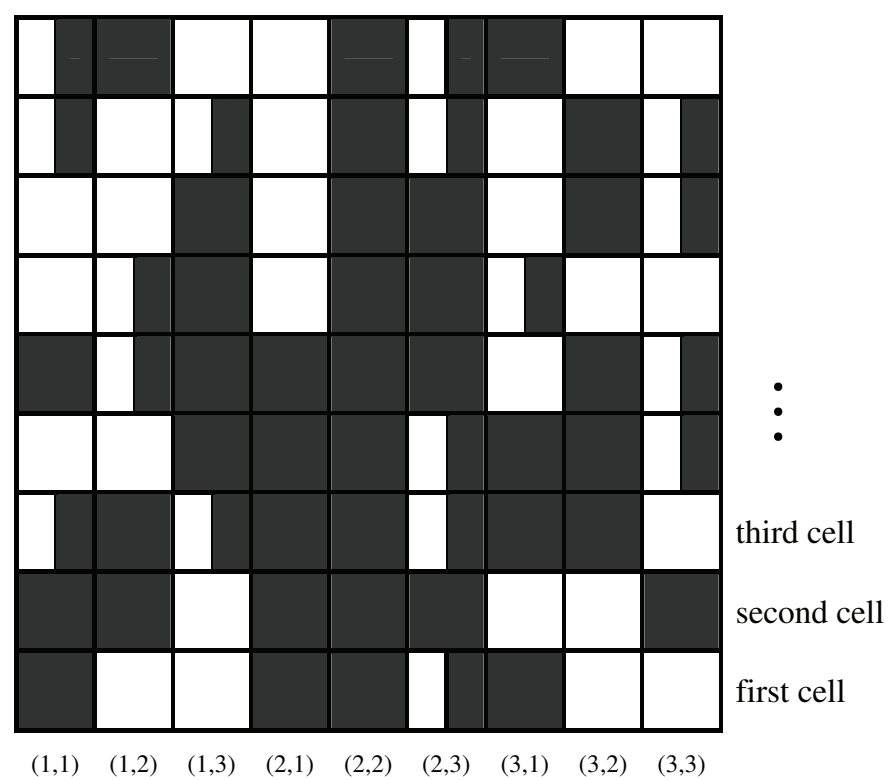

Figure 4.

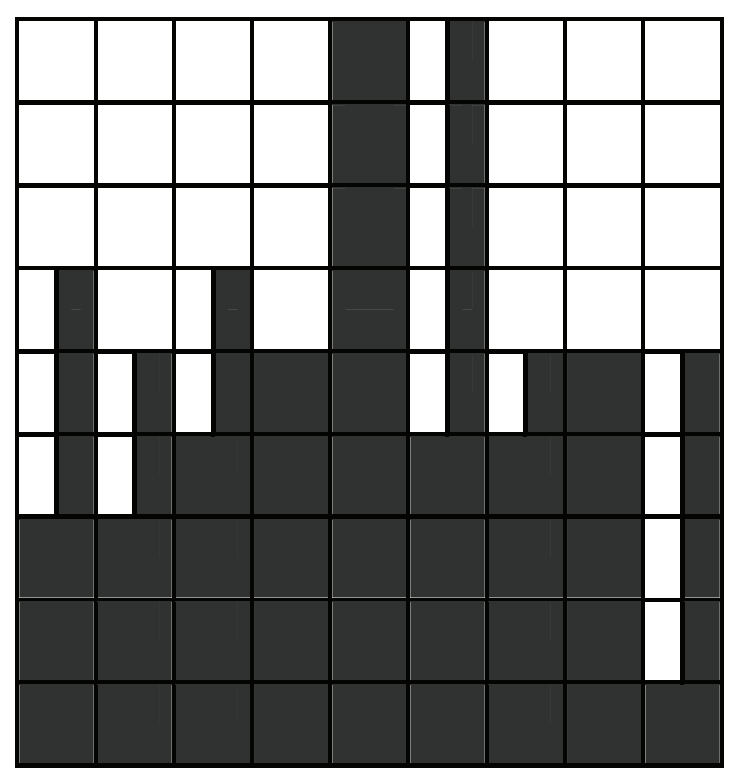

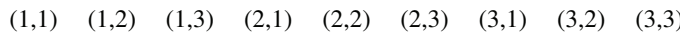

Figure 5. 
Example 2. Now let us consider the chess board, part of which is illustrated in Fig. 9. Each couple of squares on the board is divided by a stripe of non-zero width. The board squares are denoted in the standard way by " $a_{1}$ ", " $a_{2}$ ", $\ldots$, " $h_{8}$ " and they have side length of 2 .

Let us place a coin of surface 1 and let us toss it $n$ times, each time having it falling on the chess board. After each tossing, we assign the pairs $\langle a, b\rangle$ to the squares on which the coin has fallen, where $a$ denotes the surface of the coin that belongs to the respective chess square, while $b$ is the surface of the coin that lies on one or more neighbouring squares. Obviously, $a+b<1$.

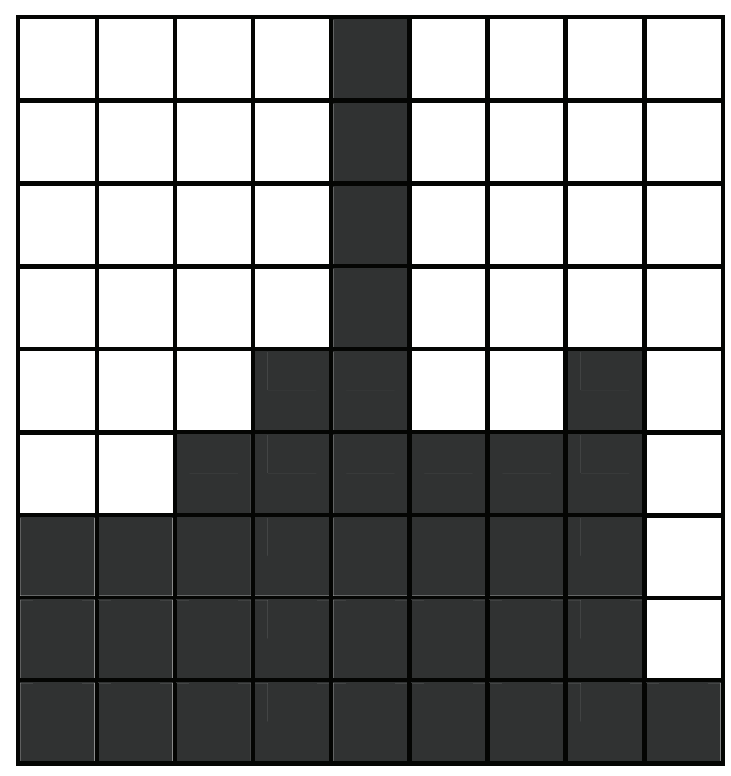

$\begin{array}{llllllll}(1,1) & (1,2) \quad(1,3) \quad(2,1) \quad(2,2) \quad(2,3) \quad(3,1) \quad(3,2) \quad(3,3)\end{array}$

Figure 6.

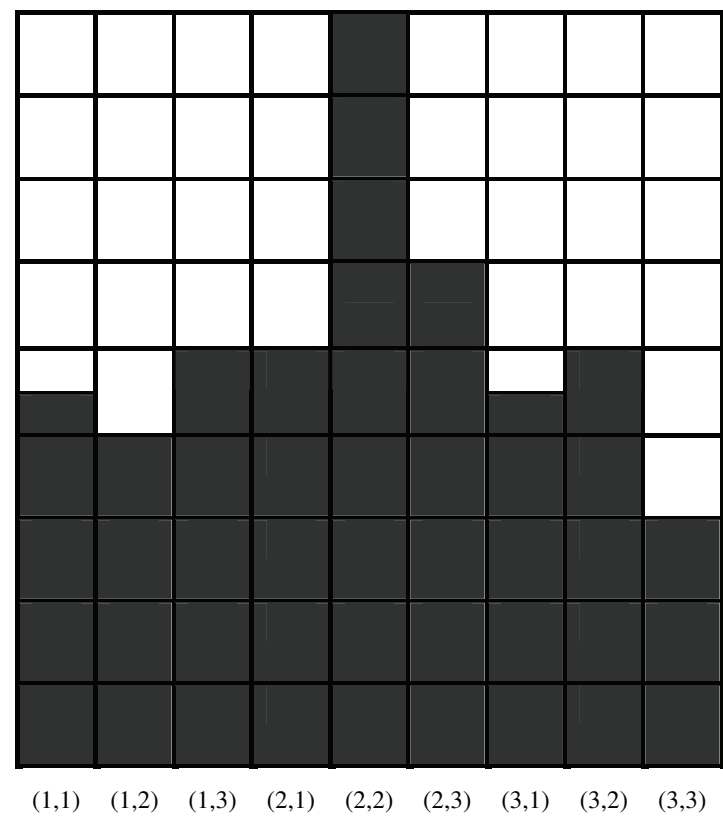

Figure 7. 
In this example, it is possible to have two specific cases:

- If the tossed coin falls on one square only, then it will be assigned the pair of values $\langle 1,0\rangle$. This case is possible, because the radius of the coin is $\sqrt{\frac{1}{\pi}}$ while its diameter is $2 \sqrt{\frac{1}{\pi}}<2$.

- If the tossed coin falls on a square and its neighbouring zone, without crossing another board square, then it will be assigned the pair of values $\langle a, 0\rangle$; where $0<a<1$ is the surface of this part of the coin that lies on the respective square.

Obviously, the tossed coin cannot fall on more than 4 squares at a time. Let us draw a table, having 64 columns, that will represent the number of the squares on the chess board, and $n$ rows, that will stand for the number of tossings. On every toss, enter pairs of values in no more than 4 columns at a time. However, despite assigning pairs of numbers to each chess square, we may proceed by colouring the square in black (rectangle with width $a$ ), white (rectangle of width $b$ ) and leave the rest of the square white, as shown in Fig. 10.

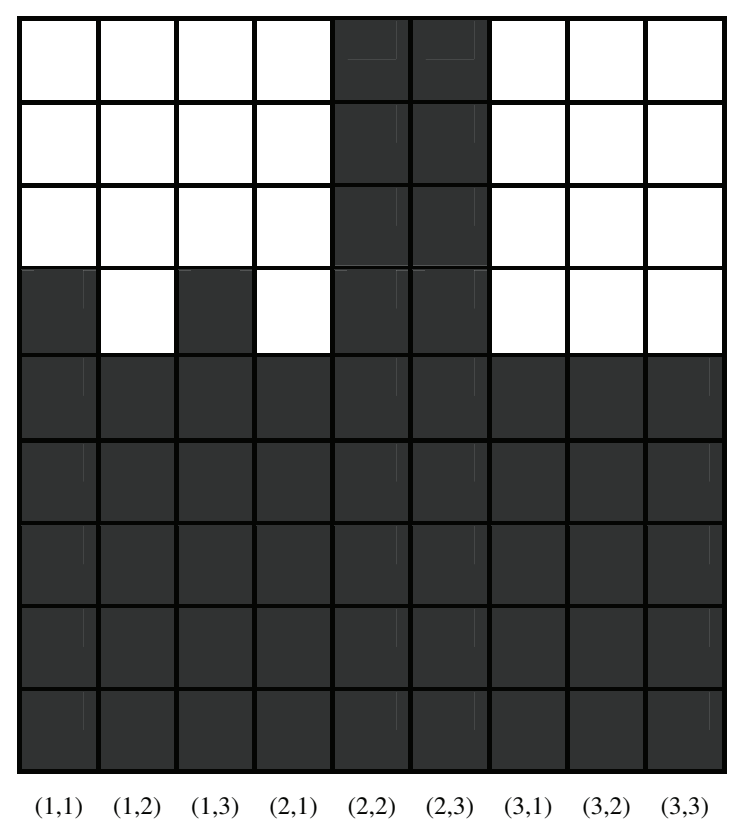

Figure 8.

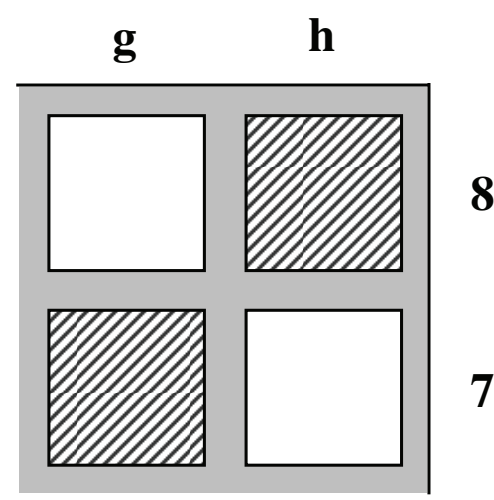

Figure 9. 


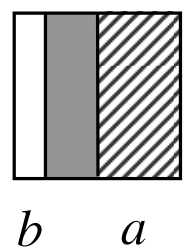

Figure 10 .

After $n$ tossings of the coin, we rearrange the squares by placing the black and/or grey squares to the bottom of the table. Thus we obtain a histogram that is analogous to the one from the first example. We can also build a histogram of necessity, a histogram of possiblity and an average histogram.

\section{GN-models of the collaborative Data Mining processes}

Following [201], we mention that "collaborative DM aims to combine the results generated by isolated experts, by enabling the collaboration of geographically dispersed laboratories and companies." The definition of the concept of a GN is a guarantee that the separate components of the collaborative DM processes can be represented by synchronized subnets of a larger GN.

\section{GN-descriptions of the different kinds of automatic theorem proving}

There are some publications devoted to descriptions by Petri nets and some extensions of these (as, for instance, Predicative-transition nets, colour nets, and so on; see, for example, [128, 129, $164,315]$ ); processes in the area of automatic theorem proving are also known (see, for example, $[85,131,173,265,296,303,307])$. Among the first publications in this area was [296].

Subsequently, the ideas from this paper were transformed into a series of papers which were devoted to GN-models of expert systems. The GNs constructed in [296] give the possibility of tracing the processes of forward and backward reasoning in automatic theorem proving. The models described there sound obsolete and the need for their modernization is urgent. When this happens, a GN-description of Skolem's procedure is to be proposed and it will work also for the intuitionistic fuzzy values of the variables. This will allow the use of intuitionistic fuzzy interpretations of the standard logical operations and quantifiers, and the use of the modal and temporal operators in the antecedents of the rules as well.

\section{Turing machine and finite automata of different types}

Practically, all types of Turing machines and finite automata were described by GNs in the middle of the 1980s (see, for example, [24]). Now, a very important, although somewhat embarrassing is the question: "Can an example of a process be found so that a Turing machine cannot describe it, but a GN can?". At the moment, we do not have answer of this question, but it is possible when 
the GN-models of semantic networks and the GNs of the process of natural language speaking are constructed, this question can be solved positively and, therefore, Church's thesis would fail. In [36], following [46] it was described a GN that realizes Kolmogorov's algorithm (see [171]) for which D. Grigoriev asserted in [139] is stronger than Turing machine.

\section{Programming languages LISP and PROLOG, and their modifications}

Up to now, there have been no attempts to describe these languages by means of GNs, but the possibility of describing the work of algorithmic languages by GNs and the ways of ESs description by GNs give a sufficient reason to assert that such GNs can be constructed.

In [52], the idea for an Intuitionistic Fuzzy Prolog was described. Unfortunately, it was not realized. Now, having in mind that the theory of IFSs was essentially extended during the last 30 years, the author plans to repeat the attempt to introduce a new version of an Intuitionistic Fuzzy Prolog. It will give to the user essentially more possibilities.

\section{Intellectual games}

Up to now no serious attempts to describe intellectual games by GNs have been undertaken. There are some simple (unpublished) attempts to construct GN-models for chess. In one of them, each of the 32 chess pieces is interpreted as a GN-token that has as a current characteristic the piece's place on the chess board. Other interpretations are possible, too. For example, the GN can initially have only one token with an initial characteristic

"the initial locations of the chess pieces on the chess board".

Each of the existing tokens will split into as many tokens as possible (the moves the corresponding player can make legally), independently on their sense, and these tokens will obtain the next current characteristic in the above form. After this, all possible moves can be estimated and the token with the best characteristic will remain; all other tokens will leave the net. It is possible that some modifications of the GNs will need to be used (for example, the opposite GNs). In practice, the situation about the other games is similar.

The first step towards modelling the process of searching for a path in a labyrinth is introduced in [104]. There, the process is described in a sufficiently general form, and some of the possible labyrinth generalizations are described.

The motion in such a generalized form within the labyrinth is described in the context of the already existing GN-model, where only the transition condition predicates and tokens' characteristic functions are changed. When the labyrinth has a tree structure, the motion in the labyrinth can be abridged and this will result in a simplification of the GN-model. In this case, the problem of new GN-model construction which will result in new algorithms for moving a guaranteed minimal length of the transfer, minimal time for searching, and so on, will be 
generated. In [104], it is assumed that complete information about the architecture of the labyrinth is in the GN-model (represented by token characteristics). If this information is absent, then the algorithms (and their GN-realizations) must be constructed. They can be based, for example, on the ideas of intuitionistic fuzziness.

\section{Some other trends for future GN-interpretations}

In [193], it is mentioned that there are several trends for future research and implementation, including:

- Active DM - closing the loop, as in control theory, where changes to the system are made according to the knowledge discovery in databases (KDD) results and the full cycle starts again. Stability and controllability, which will be significantly different in these types of systems, need to be well-defined.

- Full taxonomy - for all the nine steps of the KDD process. We have shown a taxonomy for the DM methods, but a taxonomy is needed for each of the nine steps. Such a taxonomy will contain methods appropriate for each step (even the first one), and for the whole process as well.

- Meta-algorithms - algorithms that examine the characteristics of the data in order to determine the best methods, and parameters (including decompositions).

- Benefit analysis - to understand the effect of the potential KDD or DM results on the enterprise.

- Problem characteristics - analysis of the problem itself for its suitability to the KDD process.

- Mining complex objects of arbitrary type - Expanding Data Mining inference to include also data from pictures, voice, video, audio, etc. This will require adapting and developing new methods (for example, for comparing pictures using clustering and compression analysis).

- Temporal aspects - many data mining methods assume that discovered patterns are static. However, in practice patterns in the database evolve over time. This poses two important challenges. The first challenge is to detect when concept drift occurs. The second challenge is to keep the patterns up-to-date without inducing the patterns from scratch.

- Distributed Data Mining - The ability to seamlessly and effectively employ Data Mining methods on databases that are located in various sites. This problem is especially challenging when the data structures are heterogeneous rather than homogeneous.

- Expanding the knowledge base for the KDD process, including not only data but also extraction from known facts to principles (for example, extracting from a machine its principle, and thus being able to apply it in other situations). 
- Expanding Data Mining reasoning to include creative solutions, not just the ones that appear in the data, but being able to combine solutions and generate another approach.

Elements of all these trends can be represented by GN-tools and this will be one of our future research aims.

\section{Some other trends for future IVIF-evaluations}

The present research aims to offer a new look on different aspects and procedures of Data Mining from the point of view of IVIFSs.

In all the commented areas of Data Mining, we see the application of interval-valued intuitionistic fuzziness as a tool for more precise estimation, which takes into account possibly simultaneously opposite patterns of behaviour, as well as uncertainty.

In [314], an idea for a new direction in AI is formulated by L. Zadeh, based on the concept of a granule. But, by the moment there is not a good formal definition of this concept. Probably, the estimations of the IVIFS-elements can be used for a model. Indeed, the geometrical interpretation of an IVIFS-element $x$ is given in Fig. 11.

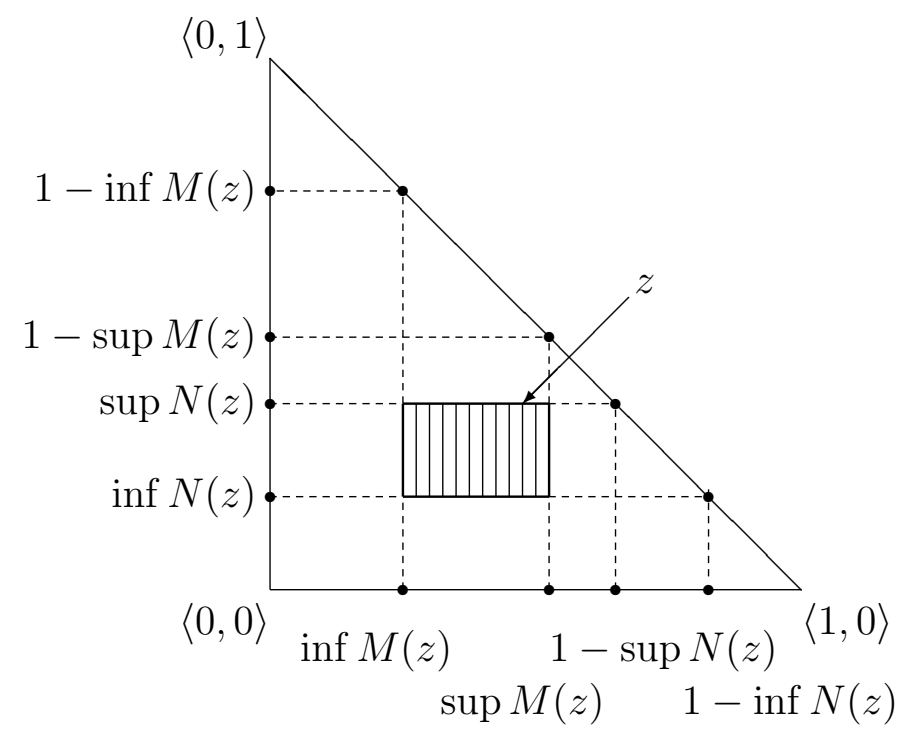

Figure 11.

Let $E$ be a universe,

$$
A=\{\langle x, M(x), M(x)\rangle \mid x \in E\}
$$

be an IVIFS, and $z \in E$ be a fixed element of the IVIFS. A granule can be defined as the set

$$
G_{\text {crisp }}(z)=\{y \mid y \in E \& \mu(y) \in M(z) \& \nu(y) \in N(z)\}
$$

(crisp form) or

$$
G_{I F S}(z)=\{\langle y, \mu(y), \nu(y)\rangle \mid y \in E \& \mu(y) \in M(z) \& \nu(y) \in N(z)\}
$$

(intuitionistic fuzzy form). 
Of course, this is only a first step of the development of this idea that will be developed in the future.

We assume that solving each of the above problems or, of course, all of them, will promote not only the theory and application of GNs, but also the research in the area of DM, too.

Bearing in mind all of the above, we think that it is clear that GNs can really make a claim for a place within DM. How central is this place? That will depend on how successfully the problems above can be solved.

How shall we benefit from having the possibility of describing all the above areas by GNs? First, this will mean that these DM-tools have a common basis, a common language by means of which all separate tools can be described, and second, we shall be able to transform methods already developed (like GN-models) from one DM-tool to another. This can be achieved by GN operations and operators, as we will discuss shortly, below.

Finally, we must note that the thesis formulated in the introduction may be an overstatement, but nevertheless it could turn out to be true, at least partially.

\section{Acknowledgements}

This paper has been partially supported by the Bulgarian National Science Fund under the Grant Ref. No. Ref. No. DN 02/10 "New Instruments for Knowledge Discovery from Data and their Modelling".

\section{References}

[1] Aladjov, H., Atanassov, K. \& Shannon, A. (2002). Generalized net model of temporal learning algorithm for artificial neural networks. Proceedings of First International IEEE Conf. on Intelligent Systems, Vol. 1, 190-193.

[2] Alexieva, J., Choy, E. \& Koycheva, E. (2007). Review and bibloigraphy on generalized nets theory and applications. In:-A Survey of Generalized Nets (E. Choy, M. Krawczak, A. Shannon and E. Szmidt, Eds.), Raffles KvB Monograph, No. 10, 207-301.

[3] Andonov, V. (2008). On some properties of one Cartesian product over intuitionistic fuzzy sets. Notes on Intuitionistic Fuzzy Sets, 14(1), 12-19.

[4] Andonov, V. (2013). Intuitionistic fuzzy generalized nets with characteristics of the places of Types 1 and 3. Notes on Intuitionistic Fuzzy Sets, 19(3), 99-110.

[5] Andonov, V. (2014). Reduced Generalized Nets with Characteristics of the Places. International Journal “Information Models and Analyses”, 3(2), 113-125.

[6] Andonov, V. (2017). Generalized Nets with Characteristics of the Arcs. Compt. rend. Acad. bulg. Sci., 70(10), 1341-1347. 
[7] Andonov, V., \& Atanassov, K. (2013). Generalized nets with characteristics of the places. Compt. rend. Acad. bulg. Sci., 66(12), 1673-1680.

[8] Andreev, S., Atanassov, K., \& Sotirov, S. (2014). Generalized net model of a social network with intuitionistic fuzzy estimation. Notes on Intuitionistic Fuzzy Sets, 20(3), 72-83.

[9] Andrew, A. (1983). Artificial Intelligence, Abacus Press, Devon.

[10] Angelov, P. (2013). Autonomous Learning Systems, John Wiley \& Sons, Chichester.

[11] Angelov, P., Filev, D., \& Kasabov, N. (2010). Evolving Intelligent Systems, John Wiley \& Sons, Hoboken.

[12] Antonov, A. (2005). Presentation of neuron by generalized net. Issues in the Representation and Processing of Uncertain Imprecise Information: Fuzzy Sets, Intuitionistic Fuzzy Sets, Generalized Nets, and Related Topics, Akademicka Oficyna Wydawnictwo EXIT, Warsaw, $1-10$.

[13] Antonov, A., \& Hadjitodorov, S. (2012). Concurrent algorithm for learning of neural networks. IEEE 6th International Conference "Intelligent Systems” 2012, 225-228.

[14] Atanassov, K. (1981). Algebraic aspect of E-nets. Proc. of Int. Symp. "Automation of Sci. Research”, Varna, October, 143-148. (in Russian).

[15] Atanassov, K. (1983). Intuitionistic fuzzy sets, VII ITKR's Session, Sofia, June 1983 (Deposed in Central Sci. - Techn. Library of Bulg. Acad. of Sci., 1697/84) (in Bulg.). Reprinted: Int. J. Bioautomation, 2016, 20(S1), S1-S6.

[16] Atanassov K. (1984). Conditions in generalized nets. Proc. of the XIII Spring Conf. of the Union of Bulg. Math., Sunny Beach, April 1984, 219-226.

[17] Atanassov, K. (1985). The generalized nets and the other graphical means for modelling. AMSE Review, 2(1), 59-64.

[18] Atanassov, K. (1986). Intuitionistic fuzzy sets. Fuzzy sets and Systems, 20(1), 87-96.

[19] Atanassov, K. (1986). Generalized nets and the classes of reduced generalized nets resulting from them. AMSE Review, 3(4), 1-6.

[20] Atanassov K. (1987). Generalized index matrices. Comptes rendus de l'Academie Bulgare des Sciences, 40(11), 15-18.

[21] Atanassov, K. (1987). The generalized E-nets - predecessors of the generalized nets. AMSE Review, 5(3), 5-9.

[22] Atanassov, K. (1990). A generalized net, representing the travelling salesman problem. AMSE Review, 14(4), 61-64. 
[23] Atanassov, K. (1990). The generalized net which represents all Petri nets. AMSE Review, 12(3), 33-37.

[24] Atanassov, K. (1991). Generalized Nets, World Scientific, Singapore.

[25] Atanassov, K. (1992). Generalized nets and extensions of the travelling salesman problem. AMSE Review, 21(2), 16-26.

[26] Atanassov, K. (1992). Introduction in Generalized Nets Theory, Pontica-Print, Bourgas, (in Bulgarian).

[27] Atanassov, K. (1993). Generalized nets and some travelling salesman problems. In: Applications of Generalized Nets. (K. Atanassov, Ed.). World Scientific, Singapore, 68-81.

[28] Atanassov, K. (1994). Remark on intuitionistic fuzzy expert systems. BUSEFAL, 59, 71-76.

[29] Atanassov, K. (1997). Generalized nets and artificial intelligence. Advances in Modelling \& Analysis, B, 37(1-2), 37-51.

[30] Atanassov, K. (1997). Generalized Nets and Systems Theory, Sofia, Academic Publishing House "Prof. M. Drinov".

[31] Atanassov, K. (1998). Generalized Nets in Artificial Intelligence. Vol. 1: Generalized nets and Expert Systems, "Prof. M. Drinov" Academic Publishing House, Sofia.

[32] Atanassov, K. (1999). Intuitionistic Fuzzy Sets, Springer, Heidelberg.

[33] Atanassov, K. (2000). Generalized net models of special abstract processes. In: Proc. of the Conf. “Bioprocess systems'2000”, 11-13 Sept., Sofia, I.4-I.10.

[34] Atanassov, K. (2001). Generalized nets as tools for modelling in the area of the artificial intelligence. Advanced Studies in Contemporary Mathematics, 3(1), 21-42.

[35] Atanassov, K. (2004). Generalized nets as tools for modelling, optimization and simulation in the area of the Artificial Intelligence. Soft Computing Foundations and Theoretical Aspects (K. Atanassov, O. Hryniewicz, J. Kacprzyk, Eds.), Academicka Oficyna Wydawnicza EXIT, Warszawa, 19-51.

[36] Atanassov, K. (2007). On Generalized Nets Theory, "Prof. M. Drinov" Academic Publishing House, Sofia.

[37] Atanassov, K. (2012). On Intuitionistic Fuzzy Sets Theory, Springer, Berlin.

[38] Atanassov, K. (2014). Index Matrices: Towards an Augmented Matrix Calculus, Springer, Cham. 
[39] Atanassov, K. (2015). Intuitionistic fuzzy logics as tools for evaluation of Data Mining processes, Knowledge-Based Systems, 80, 122-130.

[40] Atanassov, K. (2018). Interval-valued intuitionistic fuzzy sets as tools for evaluation of data mining processes. Notes on Intuitionistic Fuzzy Sets, 24(4), 190-202.

[41] Atanassov, K. (2018). n-Dimensional extended index matrices. Advanced Studies in Contemporary Mathematics, 28(2), 245-259.

[42] Atanassov, K. (2020). Generalized Nets and Intuitionistic Fuzziness in Data Mining, "Prof. M. Drinov" Academic Publishing House, Sofia.

[43] Atanassov, K., \& Aladjov, H. (2000). Generalized Nets in Artificial Intelligence. Vol. 2: Generalized nets and Machine Learning. "Prof. M. Drinov" Academic Publishing House, Sofia.

[44] Atanassov, K., Chountas, P., Kolev, B. \& Sotirova, E. (2006). Generalized net model of a self-developing expert system. Proc. of the 10th international conference on Intuitionistic fuzzy sets, Sofia, 28-29 October, 35-40.

[45] Atanassov, K., Chountas, P., Kolev, B., \& Sotirova, E. (2006). Generalized net model of an expert system with temporal components. Advanced Studies in Contemporary Mathematics, 12(2), 255-289.

[46] Atanassov, K., \& Dantchev, S. (2007). Generalized net realizations of Kolmogorov's algorithm. Issues in Intuitionistic Fuzzy sets and Generalized Nets, 4, 65-74.

[47] Atanassov, K., Daskalov, M., Georgiev, P., Kim, S., Kim, Y., Nikolov, N., Shannon, A., \& Sorsich, J. (1997) Generalized Nets in Neurology, Academic Publishing House "Prof. M. Drinov", Sofia.

[48] Atanassov, K., \& Dimitrov, E. (1985). On the representation of M-nets by generalized nets. Proc. of the XIV Spring Conf. of the Union of Bulg. Math., Sunny Beach, April 1985, 317-322.

[49] Atanassov, K., \& Dimitrov, E. (1987). Theorem for representation of the generalized modification of Petri nets by generalized nets. AMSE Review, 5(1), 8-13.

[50] Atanassov, K., \& Dimitrov, E. (1987). Theorem for representation of the Self-modification nets by generalized nets. AMSE Review, 5(3), 1-4.

[51] Atanassov, K., Dincheva, E., Matev, D., \& Stefanova-Pavlova, M. (1989). Generalized net representation of flexible manufacturing systems. Methods of Operations Research, Vol. 63., Proc. of the 14-th Symposium on Operations Research. Ulm, Sept., 521-528.

[52] Atanassov, K., \& Georgiev, Ch. (1993). Intuitionistic fuzzy Prolog. Fuzzy sets and Systems, 53(1), 121-128. 
[53] Atanassov, K.,\& Gluhchev, G. (2007). Generalized net model of the automatic natural language translation. Proceedings of the Eighth Int. Workshop on Generalized Nets, Sofia, 26 June 2007, 32-37.

[54] Atanassov, K., Gluhchev, G., Hadjitodorov, S., Kacprzyk, J., Shannon, A., Szmidt, E., \& Vassilev, V. (2006). Generalized Nets Decision Making and Pattern Recognition, Warsaw School of Information Technology, Warszawa.

[55] Atanassov, K., Gluhchev, G., Hadjitodorov, S., Shannon, A., \& Vasilev, V. (2003). An example of the aplication of generalized nets in Artificial Intelligence. Compt. Rend. de Comptes Rendus de l'Academie bulgare des Sciences, 56(5), 13-18.

[56] Atanassov, K., Gluhchev, G., Hadjitodorov, S., Shannon, A., \& Vassilev, V. (2003). Generalized Nets and Pattern Recognition. KvB Visual Concepts Pty Ltd, Monograph No. 6, Sydney, 2003.

[57] Atanassov, K., \& Hadjiski, M. (2010). Generalized nets and intelligent systems. Int. Journal of General Systems, 39(5), 457-470.

[58] Atanassov, K., Kacprzyk, A., \& Sotirova, E. (2014). A Novel Generalized Net Model of the Executive Compensation Design. Journal of Automation, Mobile Robotics \& Intelligent Systems, 8(3), 29-39.

[59] Atanassov, K., Krawczak, M., \& Sotirov, S. (2010). Generalized net model for parallel optimization of feed-forward neural network with variable learning rate backpropagation algorithm. Advanced Intelligent systems from theory to practice, Springer, 361-372.

[60] Atanassov, K., Mavrov, D., \& Atanassova, V. (2014). Intercriteria decision making: A new approach for multicriteria decision making, based on index matrices and intuitionistic fuzzy sets. Issues in Intuitionistic Fuzzy Sets and Generalized Nets, 11, 1-8.

[61] Atanassov, K., Orozova, D., Sotirova, E., Chountas, P., \& Tasseva, V. (2007). Generalized net model of expert system validity testing process. Proc. of the international conference of $B F U, 165-173$.

[62] Atanassov, K., Pasi, G., \& Yager, R. (2002). Intuitionistic fuzzy interpretations of multi-measurement tool multi-criteria decision making. Proceedings of the Sixth International Conference on Intuitionistic Fuzzy Sets (J. Kacprzyk and K. Atanassov, Eds.), Varna, 13-14 Sept., Notes on Intuitionistic Fuzzy Sets, 8(3), 66-74.

[63] Atanassov, K., Pasi, G., \& Yager, R. (2002). Intuitionistic fuzzy interpretations of multiperson multi-criteria decision making. Proceedings of 2002 First International IEEE Conference on Intelligent Systems, Vol. 1, 115-119.

[64] Atanassov, K., Pasi, G.,\& Yager, R. (2005). Intuitionistic fuzzy interpretations of multicriteria multi-person and multi-measurement tool decision making. International Journal of Systems Science, 36(14), 859-868. 
[65] Atanassov K., Pasi, G., Yager, R., \& Atanassova, V. (2003). Intuitionistic fuzzy graph interpretations of multi-person multi-criteria decision making. Proc. of the Third Conf. of the European Society for Fuzzy Logic and Technology EUSFLAT' 2003, Zittau, 10-12 Sept. 2003, 177-182.

[66] Atanassov, K., \& Pencheva, T. (2013). Generalized net model of simple genetic algorithm modifications. Issues in Intuitionistic Fuzzy Sets and Generalized Nets, 10, 97-106.

[67] Atanassov, K., Peneva, D., Taseva, V., Sotirova, E., \& Orozova, D. (2006). Generalized net model of expert systems with frame - Type Data Base with intuitionistic fuzzy estimations. First International Workshop on Intuitionistic fuzzy sets, Generalized nets and Knowledge Engineering, London, UK, 2-6 September 2006, 111-116.

[68] Atanassov, K., \& Sotirov, S. (2006). Optimization of a neural network of self-organizing maps type with time-limits by a generalized net. Advanced Studies on Contemporary Mathematics, 13(2), 213-220.

[69] Atanassov, K., Sotirov, S., \& Antonov, A. (2007). Generalized net model for parallel optimization of feed-forward neural network. Advanced Studies in Contemporary Mathematics, 15(1), 109-119.

[70] Atanassov, K., Sotirov, S., \& Shannon, A. (2012). Generalized net model of the hierarchical neural networks. Proceedings of the 13th International Workshop on Generalized Nets, 29 October 2007, London, UK, 8-14.

[71] Atanassov, K., Sotirova, E., \& Bureva, V. (2013). On index matrices. Part 4: New operations over index matrices. Advanced Studies in Contemporary Mathematics, 23(3), $547-552$.

[72] Atanassov, K., Sotirova, E., \& Orozova, D. (2006). Generalized Net Model of Expert Systems with Frame-Type Data Base. Jangjeon Mathematical Society, 9(1), 91-101.

[73] Atanassov, K., Szmidt, E., \& Kacprzyk, J. (2013). On intuitionistic fuzzy pairs. Notes on Intuitionistic Fuzzy Sets, 19(3), 1-13.

[74] Atanassov, K., Szmidt, E., Kacprzyk, J., \& Atanassova, V. (2015). Intuitionistic fuzzy approach to the preference degree estimations. Comptes Rendus de l'Academie bulgare des Sciences, 68(1), 25-32.

[75] Atanassov, K., Szmidt, E., Kacprzyk, J., \& Atanassova, V. (2017). An approach to a constructive simplification of multiagent multicriteria decision making problems via intercriteria analysis. Comptes rendus de l'Academie bulgare des Sciences, 70(8), $1147-1156$.

[76] Atanassova, V. (2012). Generalized nets with volumetric tokens. Comptes rendus de l'Academie bulgare des Sciences, 65(11), 1489-1498. 
[77] Atanassova, V., \& Atanassov, K. (2011). Ant colony optimization approach to tokens' movement within generalized nets. Lecture Notes in Computer Science, Vol. 6046, Springer, Berlin, 240-247.

[78] Atanassova, V., Doukovska, L., Atanassov, K., \& Mavrov, D. (2014). InterCriteria Decision Making approach to EU Member States Competitive Analysis. Proc. of 4th Int. Symposium on Business Modeling and Software Design, Luxembourg, Grand Duchy of Luxembourg, 24-26 June 2014, 289-294.

[79] Atanassova, V., Fidanova, S., Chountas, P., \& Atanassov, K. (2012). A generalized net with an ACO-algorithm optimization component, Lecture Notes in Computer Science, Vol. 7116, 190-197.

[80] Atanassova, V., Mavrov, D., Doukovska, L., \& Atanassov, K. (2014). Discussion on the threshold values in the InterCriteria Decision Making approach. Notes on Intuitionistic Fuzzy Sets, 20(2), 94-99.

[81] Behera, H.S., Mohapatra, D.P. (Eds.) (2016). Computational Intelligence in Data Mining. Vol. 1, Springer, New Delhi.

[82] Behera, H.S., Mohapatra, D.P. (Eds.) (2016). Computational Intelligence in Data Mining. Vol. 2, Springer, New Delhi.

[83] Berti-Equille, L. (2007). Measuring and modelling data quality for quality-awareness in data mining. In:- Quality Measures in Data Mining (F. Guillet and H. Hamilton, Eds.), Springer, Berlin, 101-126.

[84] Beuerlein, B. et al. (2018). Big Data and the Role of the Actuary. American Academy of Actuaries, Washington, June 2018.

[85] Bonacina, M. (1987). Petri nets for knowledge representation. Petri Nets Newsletter, 27, 28-36.

[86] Boyd, D., \& Crawford, K. (2012). Critical questions for Big Data. Information, Communication \& Society, 15(5), 662-679.

[87] Bramer, M. (2013). Principles of Data Mining. Springer, London.

[88] Bull, L., Ester, B.-M., \& Holmes, J. (2008). Learning classifier systems in data mining: An introduction. In:-Learning Classifier Systems in Data Mining (L. Bull, B.-M. Ester, J. Holmes, Eds.), Springer, Berlin, 1-15.

[89] Bureva, V. (2012). Generalized net model of the creating of associative rules. Annual of “Informatics” Section, Union of Scientists in Bulgaria, 5, 73-83 (in Bulgarian).

[90] Bureva, V. (2014). Intuitionistic fuzzy histograms in grid-based clustering. Notes on Intuitionistic Fuzzy Sets, 20(1), 55-62. 
[91] Bureva, V., Chountas, P., \& Atanassov, K. (2012). A generalized net model of the process of decision tree construction. 13th Int. Workshop on Generalized Nets, London, 29 October $2012,1-7$.

[92] Bureva, V., \& Sotirova, E. (2013). Generalized net of the process of association rules discovery by Eclat algorithm using weather databases. 14-th International Workshop on Generalized Nets, IWGN'2013, Burgas, 29-30 November, 1-10.

[93] Bureva, V., Sotirova, E., \& Atanassov, K. (2014). Hierarchical generalized net model of the process of clustering. Issues in Intuitionistic Fuzzy Sets and Generalized Nets, 11, 73-80.

[94] Bureva, V., Sotirova, E., \& Atanassov, K. (2014). Hierarchical generalized net model of the process of selecting a method for clustering. Proceedings of the 15-th International Workshop on Generalized Nets, 39-48.

[95] Bureva, V., Sotirova, E., \& Chountas, P. (2015). Generalized Net of the Process of Sequential Pattern Mining by Generalized Sequential Pattern Algorithm (GSP), Intelligent Systems'2014, Springer, Cham, 831-838.

[96] Bureva, V., Traneva, V., Sotirova, E., \& Atanassov, K. (2017). Index matrices and OLAPcube. Part 2: An presentation of the OLAP-analysis by index matrices. Advanced Studies in Contemporary Mathematics, 27 (4), 647-672.

[97] Bureva, V., Traneva, V., Sotirova, E., \& Atanassov, K. (2019). Index matrices and OLAPcube. Part 4: A presentation of the OLAP “drill across" operation by index matrices. Advanced Studies in Contemporary Mathematics, 29(1), 109-123.

[98] Bureva, V., Traneva, V., Sotirova, E., \& Atanassov, K. (2020). Index matrices and OLAPcube. Part 5: Index matrix operations over OLAP-cube. Advanced Studies in Contemporary Mathematics, 30(1), 69-88.

[99] Büyüközkan, G., \& Feyaioğlu, O. (2005). Accelerating the new product introduction with intelligent data mining. In:- Intelligent Data Mining: Techniques and Applications (D. Ruan, G. Chen, E. Kerre, G. Wets, Eds.), Springer, Berlin, 2005, 337-354.

[100] Chountas, P., Kolev, B., Rogova, E., Tasseva, V., \& Atanassov, K. (2007). Generalized Nets in Artificial Intelligence. Vol. 4: Generalized nets, Uncertain Data and Knowledge Engineering. "Prof. M. Drinov" Academic Publishing House, Sofia.

[101] Chountas, P., Kolev, B., Tasseva, V., \& Atanassov, K. (2007). Generalized net model for binary operations over intuitionistic fuzzy OLAP cubes. Proceedings of the Eighth Int. Workshop on Generalized Nets, Sofia, 26 June 2007, 66-72.

[102] Chountas, P., Rogova, E., \& Atanassov, K. (2011). The notion of H-IFS: An approach for enhancing the OLAP capabilities in oracle10g, International Journal of Intelligent Systems, 26(3), 262-283. 
[103] Chountas, P., Sotirova, E., Kolev, B., \& Atanassov, K. (2006). On intuitionistic fuzzy expert systems with temporal components. In:- Computational Intelligence, Theory and Applications, Springer, Berlin, 241-249.

[104] Christov, R., \& Atanassov, K. (1993). Generalized nets and labyrinths. In:- Applications of Generalized Nets, Atanassov K. (Ed.). World Scientific, Singapore, 82-84.

[105] Cios, K. J., Pedrycz, W., \& Swiniarski, R. (1998). Data Mining Methods for Knowledge Discovery, Kluwer.

[106] Cios, K., Pedrycz, W., Swiniarski, R., \& Kurgan, L. (2007). Data Mining. A Knowledge Discovery Approach, Springer, New York.

[107] Cohen, P., Cheyer, A., Wang, M., \& Baeg, S. C. (1994). OAA: An Open Agent Architecture. AAAI Spring Symposium.

[108] Cox, E. (2005). Fuzzy Modeling and Genetic Algorithms for Data Mining and Exploration, Elsevier, Amsterdam.

[109] Crespi-Reghizzi, S., \& Mandrioli, D. (1976). Some algebraic properties of Petri nets, Alma Erequeza, 45(2), 130-137.

[110] Dahan, H., Cohen, Sh., Rokach, L., \& Maimon, O. (2014). Proactive Data Mining with Decision Trees, Springer, New York.

[111] Dimitrov, E., \& Atanassov, K. (1988). Theorem for representation of M-nets by generalized nets. AMSE Review, 6, 5-12.

[112] Dimitrova, M., Vasilev, K., \& Sotirov, S. (2010). Generalized net model of the process of the prognosis biomass accumulation with neural network. Developments in Fuzzy Sets, Intuitionistic Fuzzy Sets, Generalized Nets and related topics. Vol II: Applications, System Research Institute, Polish Academy of Science. Warsaw, 2010, 79-90.

[113] Dorigo, M. (1992). Optimization, Learning and Natural Algorithms. Ph.D. thesis. Politecnico di Milano, Italy (in Italian).

[114] Dorigo, M., \& Stutzle, T. (2004). Ant Colony Optimization, MIT Press.

[115] Espinasse, B., Picolet, G., \& Chouraqui, E. (1997). Negotiation support systems: a multicriteria and multi-agent approach. European Journal of Operational Research, 103(2), 389-409.

[116] Etzion, T., \& Yoeli, M. (1983). Super-nets and their hierarchy. Theoretical Computer Science, 23, 243-272.

[117] Feys, R. (1965). Modal Logics, Gauthier, Paris. 
[118] Fidanova, S., \& Atanassov, K. (2008). Generalized net models of the process of ant colony optimization with intuitionistic fuzzy estimations. Proceedings of the Ninth International Workshop on Generalized Nets (K, Atanassov and A. Shannon, Eds.), Sofia, 4 July 2008, $1,41-48$.

[119] Fidanova, S., \& Atanassov, K. (2008). Generalized net models for the process of hybrid ant colony optimization. Comptes Rendus de l'Academie bulgare des Sciences, 61(12), 1535-1540.

[120] Fidanova, S., \& Atanassov, K. (2008). Generalized net models of the process of ant colony optimization. Issues in Intuitionistic Fuzzy Sets and Generalized Nets, 7, 108-114.

[121] Fidanova, S., \& Atanassov, K. (2010). Generalized net models and intuitionistic fuzzy estimations of the process of ant colony optimization, Issues in Intuitionistic Fuzzy Sets and Generalized Nets, 8, 109-124.

[122] Fidanova, S., \& Atanassov, K. (2010). Generalized nets as tools for modelling of the ant colony optimization algorithms. Lecture Notes in Computer Science, Vol. 5910, 326-333.

[123] Fidanova, S., Atanassov, K., \& Marinov, P. (2011). Generalized Nets in Artificial Intelligence. Vol. 5: Generalized Nets and Ant Colony Optimization. "Prof. M. Drinov" Academic Publishing House, Sofia.

[124] Fidanova, S., Marinov, P., \& Atanassov, K. (2010). Generalized net models of the process of ant colony optimization with different strategies and intuitionistic fuzzy estimations. Proceedings of the Jangjeon Mathematical Society, 13(1), 1-12.

[125] Fidanova, S., Marinov, P. \& Atanassov, K. (2014). New evaluations of ant colony optimization start nodes. Control and Cybernetics, 43(3), 471-485.

[126] Fishburn, P. (1971). A comparative analysis of Group Decision Methods. Behavioral Science, 16(6), 538-544.

[127] Freitas, A. A. (2010). A Review of Evolutionary Algorithms for Data Mining. In:- Data Mining and Knowledge Discovery Handbook (O. Maimon and L. Rokach, Eds.), Second Edition, Springer, New York, 371-400.

[128] Genrich, H. (1986). Predicate/transition nets. Lecture Notes in Computer Science, Vol. 254, 207-247.

[129] Genrich, H., \& Lautenbach, K. (1979). The analysis of distributed systems by means of predicate/transition nets. Lecture Notes in Computer Science, Vol. 70, 123-146.

[130] Geoffrey F. (2000). Big Data HPC Convergence and a bunch of other things, 02/04/2016, http://www.slideshare.net/Foxsden/big-data-hpc-convergence-and-a-bunchof-other-things. Date, C.J. An Introduction to Database Systems, 7th edn., Reading, MA: Addison-Wesley. 
[131] Giordana, A., \& Saitta, L. (1985). Modelling production rules by means of predicate/transition networks. Inf. Sciences, 35, 1-41.

[132] Gluhchev, G., Atanassov, K., Hadjitodorov, S., \& Shannon, A. (2009). A generalized net model of the process of scene analysis. Cybernetics and Information Technologies, 9(1), $13-17$.

[133] Gluhchev, G., Atanassov, K., \& Vassilev, V. (2008). A generalized net model of scene analysis process. Advances in Fuzzy Sets, Intuitionistic Fuzzy Sets, Generalized Nets and Related Topics. Vol. II: Applications, Academic Publishing House EXIT, Warszawa, 2008, 63-68.

[134] Gochev, V., \& Atanassov, K. (2004). Over generalized net reprersentation of one type of fuzzy Petri nets. Advanced Studies on Contemporary Mathematics, 8(1), 59-64.

[135] Gochev, V., Atanassov, K., \& Chountas, P. (2003). A generalized net representing the functioning and the results of the work of fuzzy Petri nets. Proc. of the 10th ISPE Int. Conf. on Concurrent Engineering "Advanced Design, Production and Management Systems", 26-30 July 2003, Madeira, 1009-1012.

[136] Gocheva, P., Sotirov, S., \& Gochev, V. (2013). Implementation of generalized nets models of feedforward neural networks. Issues in Intuitionistic Fuzzy Sets and Generalized Nets, $10,125-135$.

[137] Grabczewski, K. (2014). Meta-Learning in Decision Tree Induction, Springer, Cham.

[138] Granichin, O., Volkovich, Z., \& Toledano-Kitai, D. (2015). Randomized Algorithms in Automatic Control and Data Mining, Springer, Berlin.

[139] Grigoriev, D. (1976). Kolmogorov algorithms are stronger than Turing machines. Investigations on Constructive Mathematics and Mathematical Logic. VIII. - In: Notes on the Leningrad Branch of Steklov Mathematical Institute, 60, 29-36.

[140] Grigorova, G., Vassilev, K., \& Sotirov, S. (2013). Generalized net model of the process of the prognosis biomass accumulation using TEMPO-amine metal complexes with neural network. New trend in Fuzzy Sets, Intuitionistic Fuzzy Sets, Generalized Nets and Related Topics. Applications. Vol. II, System Research Institute, Polish Academy of Science, Warsaw, 2013, 57-66.

[141] Grosan, V., \& Abraham, A. (2011). Intelligent Systems - A Modern Approach, Springer, Berlin.

[142] Grutzner, R. (1982). Entwurtsbegleitende Verhaltensanalyse von Rechnersystemen auf der Basis von M-Netzen, Analyse und Synthese von Rechnersystemen, Problemseminar, Nassau, 1982, Teil 1, 84-88. 
[143] Grzymala-Busse, J. W. (2010). Rule induction. In:- Data Mining and Knowledge Discovery Handbook (O. Maimon and L. Rokach, Eds.), Second Edition, Springer, New York, 249-265.

[144] Gyurov, P. (1995). A generalized net representing the functioning of all coloured Petri nets and results of this functioning. Advances in Modelling \& Analysis, A, AMSE Press, 26(1), $1-9$.

[145] Haddadi, A. (1959). Communication and Cooperation in Agent Systems, Berlin, Springer.

[146] Hadjyisky, L., \& Atanassov, K. (1990). Theorem for representation of the neuronal networks by generalized nets. AMSE Review, 12(3), 47-54.

[147] Hadjyisky, L., \& Atanassov, K. (1992). A generalized net, representing the elements of one neuron network set. AMSE Review, 14(4), 55-59.

[148] Hadjyisky, L., \& Atanassov, K. (1993). Generalized nets representing the elements of neuron networks. In: Applications of Generalized Nets. (K. Atanassov, Ed.). World Scientific, Singapore, 49-67.

[149] Hadjyisky, L., \& Atanassov, K. (1993). Intuitionistic fuzzy model of a neural network. BUSEFAL, 54, 36-39.

[150] Hadjyisky, L., \& Atanassov, K. (1995). Generalized net model of the intuitionistic fuzzy neural networks. Advances in Modelling \& Analysis, AMSE Press, 23(2), 59-64.

[151] Han, J., \& Kamber, M. (2006). Data Mining: Concepts and Techniques, Morgan Kaufmann.

[152] Hand, D., Mannila, H. \& Smyth, P. (2001). Principles of Data Mining, MIT Press, Chapter 1 "Introduction", 7.

[153] Hastie, T., Tibshirani, R., \& Friedman, J. (2001). The Elements of Statistical Learning Data Mining, Inference and Prediction. Springer, New York, 2001.

[154] Hilderman, R., \& Peckham, T. (2007). Statistical methodologies from mining potentially interesting contrast sets. In:-Quality Measures in Data Mining (F. Guillet and H. Hamilton, Eds.), Springer, Berlin, 153-177.

[155] Holmes, D., \& Jain, L. (Eds.) (2012). Data Mining: Foundations and Intelligent Paradigms, Vol. 2: Statistical, Bayesian, Time Series and other Theoretical Aspects. Springer, Berlin.

[156] Holmes, D., \& Jain, L. (Eds.) (2012). Data Mining: Foundations and Intelligent Paradigms, Vol. 3: Medical, Health, Social, Biological and Other Applications. Springer, Berlin. 
[157] Holmes, D., Tweedale, J., \& Jain, L. (2012). Data mining techniques in clustering, association and classification. In:- Data Mining: Foundations and Intelligent Paradigms, Vol. 1: Clustering, Association and Classification (D. Holmes and L. jain, Eds.), Springer, Berlin, 1-6.

[158] Hong, T.-P., Chen, C.-H., Wu, Y.-L., \& Tseng, V. S. (2008). Fining active membership functions in fuzzy data mining. In:-Data Mining: Foundations and Practice (T. Y. Lin, Y. Xie, A. Wasilewska, C.-J. Liau, Eds.), Springer, Berlin, 179-196.

[159] Honko, P. (2017). Granular-Relational Data Mining, Springer, Cham.

[160] Hwang, C., \& Lin, M.J. (1987). Group Decision Making under Multiple Criteria. Methods and Applications. Lecture Notes in Economics and Mathematical Systems, Springer-Verlag.

[161] (1999) Introduction to Data Mining and Knowledge Discovery (Third Edition), Two Crows Corporation, Potomac.

[162] Jain, R., \& Pancanti, S. (1999). BIOMETRICS - Personal Verification in Network Society, Kluwer Acad. Publ., Massachusets.

[163] Jensen, K. (1981). Coloured Petri nets and the invariant-method, Theoretical Computer Science, 14(3), 317-336.

[164] Jensen, K. (1992). Coloured Petri nets. EATCS Monographs on Theoretical Computer Science. Vol. 1, Berlin, Springer.

[165] Johnson, N., \& Leone. F. (1977). Statistics and Experimental Design, John Wiley \& Sons, New York.

[166] Kasabov, N. (2007). Evolving Connectionist Systems, Springer, London.

[167] Kecman, V. (2001). Learning and Soft Computing, MIT Press.

[168] Klose, A., Nürnberger, A., Nauck, D., \& Kruse, R. (2001). Data Mining with neuro-fuzzy models.-In: Data Mining and Computational Intelligence, Springer, Berlin, 1-35.

[169] Klosgen, W., \& Zytkow, J. (Eds.) (2002). Handbook of Data Mining and Knowledge Discovery, Oxford University Press New York.

[170] Kolev, B., El-Darzi, E., Sotirova, E., Petronias, I., Atanassov, K., Chountas, P., \& Kodogiannis, V. (2006). Generalized Nets in Artificial Intelligence. Vol. 3: Generalized nets, Relational Data Bases and Expert Systems. "Prof. M. Drinov" Academic Publishing House, Sofia.

[171] Kolmogorov, A. (1953). To the definition of an algorithm. Uspekhi Mat. Nauk, 8(4), 175-176. 
[172] Kotov, V. (1978). An algebra for parallelism based on Petri nets. Lect. Notes in Comp. Sci., 64, 39-55.

[173] Koutanis, D., \& Rasshidi, R. (1987). Petri net representation of rule based expert systems. In: First Annual ESD/SMI Expert Systems Conference, 143-152.

[174] Koycheva, E. (2004). Examples of basic components in the UML, represented by generalized nets. Issues in Intuitionistic Fuzzy Sets and Generalized Nets (K. Atanassov, J. Kacprzyk and M. Krawczak, Eds.), Wydawnictwo WSISiZ, Warszawa, 79-87.

[175] Koycheva, E. (2004). Representability of extended UML sequence diagrams with loops by generalized nets. Issues in Intuitionistic Fuzzy Sets and Generalized Nets, Vol. 2 (K. Atanassov, J. Kacprzyk and M. Krawczak, Eds.), Wydawnictwo WSISiZ, Warszawa, 93-96.

[176] Koycheva, E. (2013). Entwurfsbegleitende Leistungsanalyse mit UML, MARTE und Generalisierten Netzen, Oldenbourg Velag, Munchen.

[177] Krawczak, M. (2003). textitMultilayer Neural Systems and Generalized Net Models, Akademicka Oficyna Wydawnicza EXIT, Warszawa.

[178] Krawczak, M. (2003). Modelling of adjoint neural networks by generalized nets,. 9th IEEE International Conference on Methods and Models in Automation and Robotics MMAR 2003, Miedzyzdroje (Poland), 25-28 August 2003, Technology Univ. of Szczecin, 33-42.

[179] Krawczak, M. (2003). Generalized net models of multilayer neural networks. Advanced Studies on Contemporary Mathematics, 7(1), 69-86.

[180] Krawczak, M. (2004). Generalized net modelling concept-neural networks models, computer aiding of social, economical and environment development, Systems Research Institute, Polish Academy of Sciences, Warsaw, 203-216.

[181] Krawczak, M. (2004). On a generalized net model of MLNN simulation. Soft Computing Tools, Techniques and Applications, Academicka Oficyna Wydawnicza EXIT, Warszawa, 157-171.

[182] Krawczak, M. (2004). An example of generalized nets applications to modelling of neural networks simulation, Current Issues in Data and Knowledge Engineering, Academicka Oficyna Wydawnicza EXIT, Warszawa, 297-308.

[183] Krawczak, M. (2005). Generalized net models of MLNN learning algorithms. Lecture Notes in Computer Science, 2 (3697), 25-30.

[184] Krawczak, M. (2005). Modelling of adjoint neural networks by generalized nets. Issues in the Representation and Processing of Uncertain Imprecise Information: Fuzzy Sets, Intuitionistic Fuzzy Sets, Generalized Nets, and Related Topics, Akademicka Oficyna Wydawnictwo EXIT, Warszawa, 217-227. 
[185] Krawczak, M., \& Aladjov, H. (2002). Generalized net model of backpropagation learning algorithm. Proc. of the Third Int. Workshop on Generalized Nets, Sofia, 1 October 2002, 32-36.

[186] Krawczak, M., \& Aladjov, H. (2003). Generalized net model of adjoint neural networks. Advanced Studies on Contemporary Mathematics, 7(1), 19-32.

[187] Krawczak, M., Bureva, V., Sotirova, E., \& Szmidt, E. (2016). Application of the InterCriteria decision making method to universities ranking. In: K. Atanassov, O. Castillo, J. Kacprzyk, et al. (Eds.): New Developments in Uncertainty Representation and Processing. Advances in Intuitionistic Fuzzy Sets and Generalized Nets, Springer, 365-372.

[188] Krawczak, M., El-Darzi, E., Atanassov, K., \& Tasseva, V. (2007). Generalized net for control and optimization of real processes through neural networks using intuitionistic fuzzy estimations, Notes on Intuitionistic Fuzzy Sets, 12(2), 54-60.

[189] Krawczak, M., Sotirov, S., \& Atanassov, K. (2010). Multilayer Neural Networks and Generalized Nets, Warsaw School of Information Technology, Warsaw.

[190] Krawczak, M., Sotirov, S., \& Sotirova, E. (2012). Generalized net model for parallel optimization of multilayer neural network with time limit. IEEE Intelligent Systems IS'12, 173-177.

[191] Looney, C. G. (1988). Fuzzy Petri nets for rule-based decisionmaking. IEEE Trans. on the System, Man and Cybernetics, 18(1), 178-183.

[192] Lorkowski, J., \& Kreinovich, V. (2018). Bounded Rationality in Decision Making Under Uncertainty. S., C.

[193] Maimon, O., \& Rokach, L. (2010). Introduction to Knowledge Discovery and Data Mining. In:-Data Mining and Knowledge Discovery Handbook (O. Maimon and L. Rokach, Eds.), Second Edition, Springer, New York, 1-15.

[194] Marinov, M. (2008). Shannon informational approach to intuitionistic fuzzy sets. Issues in Intuitionistic Fuzzy Sets and Generalized Nets, 7, 7-9.

[195] Marinov, M. (2012). Shannon approach to intuitionistic fuzzy information definition. Part 2. Notes on Intuitionistic Fuzzy Sets, 18(4), 59-63.

[196] Marinov, M. (2012). Intuitionistic fuzzy load balancing in cloud computing. Notes on Intuitionistic Fuzzy Sets, 18(4), 19-25.

[197] Mengov, G., Pulov, S., Atanassov, K., Georgiev, K., \& Trifonov, T. (2003). Modeling neural signals with a generalized net. Advanced Studies on Contemporary Mathematics, $7(2), 155-166$.

[198] Merlin, P. (1974). A Study of the Recoverability of Computer Systems, Ph.D. thesis, Univ. of California. 
[199] Meyer-Nieberg, S., \& Beyer, H.-G. (2007). Self-adaptation in evolutionary algorithms. In:- Parameter Setting in Evolutionary Algorithms (F. Lobo, C. Lima, Z. Michalewicz, Eds.), Studies in Computational Intelligence, No. 54, Springer, Berlin, 47-75.

[200] Montebello, M. (2018). AI Injected e-Learning, Springer, Cham.

[201] Moyle, S. (2010). Collaborative Data Mining. In:- Data Mining and Knowledge Discovery Handbook (O. Maimon and L. Rokach, Eds.), Second Edition, Springer, New York, 1029-1039.

[202] Natkin, S. (1980). Les reseaux de Petri stochastiques et leur application a l'evaluation des systems informatiques, Ph.D. thesis, June 1980.

[203] Nikolov, N. (1995). Generalized nets and semantic networks. Advances in Modelling \& Analysis, AMSE Press, 27(1), 19-25.

[204] Nikolova, M., Szmidt, E., \& Hadjitodorov, S. (2000). Generalized nets with decision making components. In: Proceedings of International Workshop on Generalized Nets, Sofia, 9 July 2000, 1-5.

[205] Nikolova, N. (1998). Generalized net representation of backpropagation neural networks. Advances in Modelling \& Analysis, AMSE Press, 1(1), 27-34.

[206] Nocera, S., Murino M., \& Cavallaro F. (2014). On the Perspective of Using Multiple Agent Multi Criteria Decision Making for Determining a Fair Value of Carbon Emissions in Transport Planning, Procedia - Social and Behavioral Sciences, 160, 274-283.

[207] Noe, J. (1975). PRO-nets: for modelling processes and processors, Techn. Rep. 75-07-15, Dept. of Comp. Sci. Univ. of Washington, Seattle.

[208] Nutt, G. (1972). The Formulation and Application of Evaluation Nets, Ph.D. thesis, Comp. Sci. Group, Univ. of Washington, Seattle.

[209] Orozova, D., \& Atanassov, K. (2012). Generalized net model of the process of selection and usage of an intelligent e-learning system, Comptes Rendus de l'Academie bulgare des Sciences, 65(5), 591-598.

[210] Orozova, D., \& Atanassov, K. (2018). Generalized net model of processes related to Big Data. Comptes rendus de l'Academie bulgare des Sciences, 71(12), 1679-1686.

[211] Orozova, D., \& Sotirova, E. (2009). Generalized net model of the applying data mining tools, Proc. of the Tenth International Workshop on Generalized Nets, Sofia, 5 December 2009, 22-26.

[212] Orozova, D., Sotirova, E., \& Chountas, P. (2009). Generalized net model of the knowledge discovery in medical databases, Bioautomation, 13(4), 281-288. 
[213] Orriols-Puig, A., \& Bernardo-Mansilla, E. (2008). Mining imbalanced data with learning classifier systems, In:- Learning Classifier Systems in Data Mining (L. Bull, B.-M. Ester, J. Holmes, Eds.), Springer, Berlin, 123-145.

[214] Parvathi, R., Sotirov, S., Gluhchev, G., \& Atanassov, K. (2011). A generalized net model of intuitionistic fuzzy image preprocessing. Comptes Rendus de l'Academie bulgare des Sciences, 64(3), 333-338.

[215] Pasi, G., Atanassov, K., Melo Pinto, P., Yager, R., \& Atanassova, V. (2003). Multiperson multi-criteria decision making: intuitionistic fuzzy approach and generalized net model. Proc. of the 10th ISPE Int. Conf. on Concurrent Engineering "Advanced Design, Production and Management Systems”, 26-30 July 2003, Madeira, 1073-1078.

[216] Pasi, G., Yager, R., \& Atanassov, K. (2004). Intuitionistic fuzzy graph interpretations of multi-person multi-criteria decision making: generalized net approach. Proceedings of Second International IEEE Conference Intelligent Systems, Varna, 22-24 June 2004, Vol. $2,434-439$.

[217] Pechenizkiy, M., Puuronen, S., \& Tsymbal, A. (2008). Does relevance matter to data mining research? In:-Data Mining: Foundations and Practice (T. Y. Lin, Y. Xie, A. Wasilewska, C.-J. Liau, Eds.), Springer, Berlin, 251-275.

[218] Pena-Ayala, A. (Ed.). (2014). Educational Data Mining, Springer, Cham.

[219] Pencheva, T. (2011). Generalized nets model of crossover technique choice in genetic algorithms. Issues in Intuitionistic Fuzzy Sets and Generalized Nets, 9, 92-100.

[220] Pencheva, T., Atanassov, K., \& Shannon, A. (2009). Modelling of a roulette wheel selection operator in genetic algorithms using generalized nets. International Journal Bioautomation, 13(4), 257-264.

[221] Pencheva, T., Atanassov, K., \& Shannon, A. (2009). Modelling of a stochastic universal sampling selection operator in genetic algorithms using generalized nets. In: Proceedings of the 10th International Workshop on Generalized Nets, Sofia, 5 December 2009, 1-7.

[222] Pencheva, T., Atanassov, K., \& Shannon, A. (2011). Generalized nets model of offspring reinsertion in genetic algorithms. Annual of "Informatics", Section of the Union of Scientists in Bulgaria, 4, 29-35.

[223] Pencheva, T., Atanassov, K., \& Shannon, A. (2011). Generalized net model of selection function choice in genetic algorithms. In: Recent Advances in Fuzzy Sets, Intuitionistic Fuzzy Sets, Generalized Nets and Related Topics. Vol. II: Applications, Warsaw, Systems Research Institute, Polish Academy of Sciences, 193-201.

[224] Pencheva, T., Atanassov, K., \& Shannon, A. (2013). Generalized nets model of rank-based fitness assignment in genetic algorithms. In: New Trends in Fuzzy Sets, Intuitionistic Fuzzy 
Sets, Generalized Nets and Related Topics. Vol. II: Applications Warsaw, Systems Research Institute, Polish Academy of Sciences, 127-136.

[225] Pencheva, T., Roeva, O., \& Shannon, A. (2008). Generalized net models of crossover operators in genetic algorithms. Proceedings of the Ninth International Workshop on Generalized Nets, Sofia, July 4 2008, 2, 64-70.

[226] Peneva, D., Tasseva, V., Kodogiannis, V., Sotirova, E., \& Atanassov, K. (2006). Generalized nets as an instrument for description of the process of expert system construction, IEEE, 760-763.

[227] Petkov, T., \& Sotirov, S. (2013). Generalized net model of the cognitive and neural algorithm for adaptive resonance theory 1. Int. J. Bioautomation, 17(4), 207-216.

[228] Petkov, T., \& Sotirov, S. (2014). Generalized net model of slow learning algorithm of unsupervised ART2 neural network, IWIFSGN'2013 Twelfth International Workshop on Intuitionistic Fuzzy Sets and Generalized Nets, Warsaw, 61-70.

[229] Petri, C.-A. (1962) Kommunication mit Automaten, Ph.D.diss., Univ. of Bonn, 1962; Schriften des Inst. fur Instrument. Math., No. 2, Bonn.

[230] Plaginakos, V., Tasoulis, D., \& Vrahatis, M. (2008). A review of major application arreas of differential evolution. In :-Advances in Differential Evolution (U. Chakraborty, Ed.), Studies in Computational Intelligence, Vol. 143, Springer, Berlin, 197-238.

[231] Popchev, I., \& Peneva, V. (1993). An algorithm for comparison of fuzzy sets. Fuzzy Sets and Systems, 60(1), 59-65.

[232] Popova, B., \& Atanassov, K. (1994). Opposite generalized nets. I. Advances in Modelling \& Analysis, AMSE Press, 19(2), 15-21.

[233] Popova, B., \& Atanassov, K. (1994). Opposite generalized nets. II. Advances in Modelling \& Analysis, AMSE Press, 19 (2), 23-28.

[234] Prestwich, S. (2008). The relation between complete and incomlpete search. In :- Hybrid Metaheuristics (C. Blum et al., Eds.), Studies in Computational Intelligence, Vol. 114, Springer, Berlin, 63-83.

[235] Radeva, V., Krawczak, M., \& Choy, E. (2002). Review and bibliography on generalized nets theory and applications. Advanced Studies in Contemporary Mathematics, 4(2), 173-199.

[236] Ramchandani, C. (1973). Analysis of Asynchronous Concurrent Systems by Timed Petri Nets, Ph.D. thesis, MIT, Cambridge, Mass., Sept 1973.

[237] Ribaric, J., \& Fratic, I. (2005). A biometric verification system based on the fusion of palmprint and face features. 4th Int. Symposium on Image and Signal Processing and Analysis, Croatia. 
[238] Riedemann, E., \& Mayer, U. (1982). Verallgemeinerte, modifizierte Petri-Netze als Modells fur MIMD-Rechner, Abteilung Informatik, Univ. of Dortmund, Forschungebericht Nr. 143.

[239] Rokach, L. (2010). A survey of clustering algorithms. In:- Data Mining and Knowledge Discovery Handbook (O. Maimon and L. Rokach, Eds.), Second Edition, Springer, New York, 269-298.

[240] Roeva, O. (2014). Bat algorithm in terms of generalized net. Proc. of 15th International Workshop on Generalized Nets, Burgas, 1-6.

[241] Roeva, O., Atanassov, K., \& Shannon, A. (2008). Generalized net for selection of genetic algorithm operators. Annual of "Informatics" Section of Union of Scientists in Bulgaria, $1,117-126$.

[242] Roeva, O., \& Atanassov, K. (2008). Generalized net model of a modified genetic algorithm. Issues in intuitionistic fuzzy sets and generalized nets, 7, 93-99.

[243] Roeva O., Atanassov, K., \& Shannon, A.(2007). Generalized net for evaluation of genetic algorithm fitness function. Proceedings of the Eighth International Workshop on Generalized Nets, Sofia, 26 June 2007, 48-55.

[244] Roeva O., \& Melo-Pinto, P. (2013). Generalized net model of Firefly algorithm. Proc. of 14th Int. Workshop on Generalized Nets, Burgas, 29 November 2013, 22-27.

[245] Roeva O., \& Michalikova, A. (2013). Generalized net model of intuitionistic fuzzy logic control of genetic algorithm parameters. Notes on Intuitionistic Fuzzy Sets, 19(2), 71-76.

[246] Roeva, O., \& Pencheva, T. (2010). Generalized net model of a multi-population genetic algorithm. Issues in Intuitionistic Fuzzy Sets and Generalized Nets, (J. Kacprzyk, M. Krawczak and E. Szmidt, Eds.), Wydawnictwo WSISiZ, Warszawa, 8, 91-101.

[247] Roeva, O., Pencheva, T., \& Atanassov, K. (2012). Generalized net of a genetic algorithm with intuitionistic fuzzy selection operator. New Developments in Fuzzy Sets, Intuitionistic Fuzzy Sets, Generalized Nets and Related Topics, Volume I: Foundations, IBS PAN (Systems Research Institute, Polish Academy of Sciences), Warsaw, 167-178.

[248] Roeva, O., Pencheva, T., Atanassov, K., \& Shannon, A. (2010). Generalized net model of selection operator of genetic algorithms. IEEE Int. Conf. on Intelligent Systems, 7-9 July 2010, London, UK, 286-289.

[249] Roeva, O., Pencheva, T., Shannon, A., \& Atanassov, K. (2013). Generalized Nets in Artificial Intelligence. Vol. 7: Generalized nets and Genetic Algorithms. "Prof. M. Drinov" Academic Publishing House, Sofia. 
[250] Roeva, O., \& Shannon, A. (2008). A Generalized net model of mutation operator of the breeder genetic algorithm. Proceedings of the Ninth International Workshop on Generalized Nets, Sofia, 4 July 2008, Vol. 2, 59-63.

[251] Roeva, O., Shannon, A., \& Pencheva, T. (2012). Description of simple genetic algorithm modifications using generalized nets. IEEE 6th Int. Conf. IS 2012, Sofia, Bulgaria, Vol. 2, $178-183$.

[252] Rud, O. P. (2001). Data Mining Cookbook, John Wiley \& Sons, Danvers.

[253] Sanchez, U. R., \& Kittler, J. (2000). Fusion of talking face biometric modalities for personal identity verification, Proc. IEEE Conf. on Acoustics, Speech, and Signal Processing, France, 1073-1076.

[254] Savov, M., \& Gluhchev, G. (2006). Signature verification via "hand-pen" motion investigation. Proc. of the 6th Int. Conf. on Recent Advances in Soft Computing (RASC 2006), (K. Sirlantzis, Ed.), UK, 490-495.

[255] Scheidat T., \& Vielhauer, C. (2005) Multimodal bviometrics for voice and handwritting. Communications and Multimedia Security, 9th IFIP Int. Conf.

[256] Schiffers, M., \& Wedde, H. (1978). Analysing program solutions of coordination problem by GP-nets. Math. Foundations of Computer Science (ed. J. Winkowski), Lect. Notes in Comp. Sci., 64, 462-473.

[257] Seifert, J., (2004). Data Mining: An Overview, CRS Report for Congress, Order Code RL31798, Dec 2004.

[258] Shannon, A., Atanassov, K., Orozova, O., Krawczak, M., Sotirova, E., Melo-Pinto, P., Petrounias, I., \& Kim, T. (2007). Generalized Nets and Information Flow Within a University. Warsaw School of Information Technology, Warsaw.

[259] Shannon, A., Langova-Orozova, D., Sotirova, E., Petrounias, I., Atanassov, K., Krawczak, M., Melo-Pinto, P., \& Kim, T. (2005). Generalized Net Modelling of University Processes. KvB Visual Concepts Pty Ltd, Monograph No. 7, Sydney.

[260] Shannon, A., Sorsich, J., \& Atanassov, K. (1996). Generalized Nets in Medicine. Academic Publishing House "Prof. M. Drinov", Sofia.

[261] Shannon, A., Sorsich, J., Atanassov, K., Nikolov, N., \& Georgiev, P. Generalized Nets in General and Internal Medicine, "Prof. M. Drinov". Academic Publishing House, Sofia, Vol. 1, 1998; Vol. 2, 1999; Vol. 3, 2000.

[262] Shapiro, S. (1979). A stochastic Petri nets with applications to modelling occupancy timed for concurrent task systems. Networks, 9, 375-379.

[263] Shmueli, G., Patel, N., \& Bruce, P. (2007). Data Mining for Business Intelligence, John Wiley \& Sons, Hoboken. 
[264] Simovici, D., \& Djeraba, Ch. (2014). Mathematical Tools for Data Mining (Second Edition), Springer, London.

[265] Sinachopoulos, A. (1987). Derivation of a contradiction by resolution using Petri nets. Petri Nets Newsletter, 26, 16-29.

[266] Sotirov, S. (2003). Modeling the algorithm backpropagation for learning of neural networks with generalized nets, Part 1. Proc. of the Fourth Int. Workshop on Generalized Nets, Sofia, 23 Sept. 2003, 61-67.

[267] Sotirov, S. (2006). Generalized net model of the accelerating backpropagation algirithm. Proceedings of the Jangjeon Mathematical Society, 217-225.

[268] Sotirov, S. (2008). Generalized net model of the art neural networks. Part 3. Developments in Fuzzy Sets, Intuitionistic Fuzzy Sets, Generalized Nets and related topics. Vol. II: Applications, System Research Institute, Polish Academy of Science. Warsaw, 257-246.

[269] Sotirov, S. (2010). Generalized net model of the time delay neural network. Issues in Intuitionistic Fuzzy Sets and Generalized Nets, 9, 125-131.

[270] Sotirov, S. (2010). Modelling distributed time-delay neural network by generalized net. Developments in Fuzzy Sets, Intuitionistic Fuzzy Sets, Generalized Nets and Related Topics. Vol. II: Applications, System Research Institute, Polish Academy of Science, Warsaw, 231-238.

[271] Sotirov, S. (2012). Modeling the backpropagation algorithm of the Elman neural network by generalized net. Proceedings of the 13th International Workshop on Generalized Nets, London, 49-55.

[272] Sotirov, S., \& Atanassov, K. (2012). Generalized Nets in Artificial Intelligence. Vol. 6: Generalized Nets and Supervised Neural Networks, "Prof. M. Drinov" Academic Publishing House, Sofia.

[273] Sotirov, S., \& Dimitrov, A. (2010). Neural network for defining intuitionistic fuzzy estimation in petroleum recognition. Issues in Intuitionistic Fuzzy Sets and Generalized Nets, 8, 74-78.

[274] Sotirov, S., \& Kodogiannis, V. (2007). Generalized net model of the Grossberg neural networks. Part 2. Issues in Intuitionistic Fuzzy Sets and Generalized Nets, 5, 130-138.

[275] Sotirov, S., \& Kodogiannis, V. (2010). Generalized net model of the Elman neural network. Eleventh Int. Workshop on GNs and Second Int. Workshop on GNs, IFSs and KE, London, 9-10 July 2010, 21-26.

[276] Sotirov, S., \& Krawczak, M. (2006). Modeling the algorithm backpropagation for learning of neural networks with generalized networks. Part 2. Issues in Intuitionistic Fuzzy Sets and Generalized Nets, 3, 65-69. 
[277] Sotirov, S., \& Krawczak, M. (2006). Modeling the work of self-organizing neural networks with generalized networks. Issues in Intuitionistic Fuzzy Sets and Generalized Nets, 3, $57-63$.

[278] Sotirov, S., \& Krawczak, M. (2008). Generalized net model of the art neural networks, Part 1. Issues in Intuitionistic Fuzzy Sets and Generalized Nets, 7, 67-74.

[279] Sotirov, S., \& Krawczak, M. (2008). Generalized net model of the art neural networks. Part 2, Issues in Intuitionistic Fuzzy Sets and Generalized Nets, 7, 75-82.

[280] Sotirov, S., \& Krawczak, M. (2010). Generalized net model of recurrent neural network. Eleventh Int. Workshop on GNs and Second Int. Workshop on GNs, IFSs and KE, London, 9-10 July 2010, 14-20.

[281] Sotirov, S., \& Krawczak, M. (2011). Modelling layered digital dynamic network by a generalized net. Issues in intuitionistic fuzzy sets and generalized nets, 9, 84-91.

[282] Sotirov, S., Krawczak, M., \& Atanassov, K. (2010). Generalized net model for parallel optimization of multilayer perceptron with momentum backpropagation algorithm, 5th International IEEE Conference “Intelligent Systems", London, 281-285.

[283] Sotirov, S., Krawczak, M., \& Atanassov, K. (2013). Modelling of brain-state-in-a-box neural network with a generalized net. In:- New Trends in Fuzzy Sets, Intuitionistic Fuzzy Sets, Generalized Nets and Related Topics. Vol. 2: Applications, SRI, Polish Academy of Sciences, 153-159.

[284] Sotirov, S., Krawczak, M., \& Kodogiannis, V. (2004). Generalized nets model of the Grossberg neural network. Part 1. Issues in Intuitionistic Fuzzy Sets and Generalized Nets, 4, 27-34.

[285] Sotirov, S., Krawczak, M., \& Kodogiannis, V. (2006). Modeling the work of learning vector quantization neural networks. Proceedings of the Seventh Int. Workshop on Generalized Nets, Sofia, 14-15 July 2006, 39-44.

[286] Sotirov, S., Kukenska, V., Hristova, M., Vardeva, I., Staneva, L., Barzov, J., Dimitrov, S., \& Stoqnova, S. (2010). Modeling the nonlinear autoregressive network with exogenous inputs with a generalized net. Developments in Fuzzy Sets, Intuitionistic Fuzzy Sets, Generalized Nets and related topics. Vol. II: Applications, System Research Institute, Polish Academy of Science. Warsaw, 223-230.

[287] Sotirov, S., Orozova, D., \& Sotirova, E. (2009). Generalized net model of the process of the prognosis with feedforward neural network. Proc. of the XVI-th International Symposium on Electrical Apparatus and Technologies, SIELA 2009, Vol. 1, 272-278.

[288] Sotirov, S., \& Sotirova, E. (2014). Generalized net model of the integrated system for early forest-fire detection. IWIFSGN'2013 Twelfth International Workshop on Intuitionistic Fuzzy Sets and Generalized Nets, Warsaw, 103-114. 
[289] Sotirova, E., Atanassov, K., \& Chountas. P. (2006). Generalized nets as tools for modelling of open, hybrid and closed systems: an example with an expert system. Advanced Studies in Contemporary Mathematics, October, 13(2), 221-234.

[290] Sotirova, E., Atanassov, K., \& Tasseva, V. (2008). Algorithms for constructing of generalized nets on the base of case study ideology. Advanced Studies in Contemporary Mathematics, 16(1), 83-103.

[291] Sotirova, E., \& Orozova, D. (2010). Generalized net model of the phases of the data mining process. Developments in Fuzzy Sets, Intuitionistic Fuzzy Sets, Generalized Nets and Related Topics. Vol. II: Applications, Warsaw, Poland, 247-260.

[292] Sotirova, E., Petkov, T., Surchev, S., \& Krawczak, M. (2011). Generalized net model of clustering with self organizing map. Developments in Fuzzy Sets, Intuitionistic Fuzzy Sets, Generalized Nets and Related Topics. Foundations and Applications, Warsaw, Poland, 239-244.

[293] Spurgin, A., \& Petkov, G. (2005). Advances simulator data mining for operators' performance assessment. In:- Intelligent Data Mining: Techniques and Applications (D. Ruan, G. Chen, E. Kerre, G. Wets, Eds.), Springer, Berlin, 487-514.

[294] Stefanova-Pavlova, M., \& Atanassov, K. (1993). Generalized net models for flexible manufacturing systems. In: Applications of Generalized Nets. (K. Atanassov, Ed.), World Scientific, Singapore, 172-207.

[295] Starke, P. (1980). Petri-Netze, Berlin, VEB Deutscher Verlag der Wissenschaften.

[296] Stoeva, S., \& Atanassov, K. (1986). Generalized net representation of production systems interpreters. In: Proc. of the Fifteenth Spring Conf. of the Union of Bulg. Math., Sunny Beach, 1986, 456-464.

[297] Surchev, S., \& Sotirov, S. (2014). Modeling the process of the color recognition with MLP using symbol visualization. IWIFSGN'2013 Twelfth International Workshop on Intuitionistic Fuzzy Sets and Generalized Nets, Warsaw, 115-124.

[298] Surchev, S., \& Sotirov, S. (2004). Modelling the process of color recognition using multilayer neural network. Issues in Intuitionistic Fuzzy Sets and Generalized Nets, 10, $143-151$.

[299] Surchev, S., Sotirov, S., \& Korneta, W. (2013). Bio-inspired artificial intelligence: A generalized net model of the regularization process in MLP. Int. J. Bioautomation, 17(3), $151-158$.

[300] Sumathi, S., \& Sivanandam, S. (2006). Introduction to Data Mining and Applications, Berlin. 
[301] Traneva, V., Bureva, V., Sotirova, E., \& Atanassov, K. (2018). Index matrices and OLAPcube. Part 1: Application of the index matrices to presentation of operations in OLAP-cube. Advanced Studies in Contemporary Mathematics, 27(2), 253-278.

[302] Traneva, V., Bureva, V., Sotirova, E., \& Atanassov, K. (2018). Index matrices and OLAPcube. Part 3: A presentation of the OLAP "InterCube Set" and "Data cube" operations by index matrices. Advanced Studies in Contemporary Mathematics, 28(3), 423-448.

[303] Valette, R. (1986). Nets in production systems. -In: Proc. of an Advanced Course "Petri nets: Applications and Relationships to Other Models of Concurrency", Bad Honnef, in Lecture Notes in Computer Science, Vol. 255, 191-217.

[304] Valette, R., \& Bako, B. (1990). Software implementation of Petri nets and compilation of rule-based systems. - In: Proc. of the 11th Int. Conf. on Application and Theory of Petri Nets, Paris, 264-283.

[305] Valk, R. (1977). Self-modifying nets, Inst. für Informatik, Univ. Hamburg, Bericht IFI-HH-B-34/77, July 1977.

[306] Vassilev, P., \& Atanassov, K. (2019). Modifications and Extensions of Intuitionistic Fuzzy Sets. "Prof. M. Drinov" Academic Publishing House, Sofia.

[307] Voss, K. (1986). Nets in Data Bases. - In: Proc. of an Advanced Course "Petri nets: Applications and Relationships to Other Models of Concurrency”, Bad Honnef, in Lecture Notes in Computer Science, Vol. 255, 97-134.

[308] Wang, J., \& Lee, H.S. (2007). Generalizing TOPSIS for fuzzy multiple-criteria group decision-making. Computers and Mathematics with Applications, 53(11), 1762-1772.

[309] Witten, H., \& Frank, E. (2005). Data Mining: Practical Machine Learning Tools and Techniques, Morgan Kaufmann.

[310] Xing, B., \& Gao, W.-J. (2014). Innovative Computational Intelligence: A Rough Guide to 134 Clever Algorithms, Springer, Cham.

[311] Yang, H., \& Huang, H.J. (2004). The multi-class, multi-criteria traffic network equilibrium and systems optimum problem. Transportation Research Part B: Methodological, 38(1), $1-15$.

[312] Yao, Y., Zhong, N., \& Zhao, Y. (2008). A conceptual framework of data mining. In:Data Mining: Foundations and Practice (T.Y.Lin, Y. Xie, A. Wasilewska, C.-J. Liau, Eds.), Springer, Berlin, 501-515.

[313] Yeh, C. H., \& Chang, Y. H. (2009). Modeling subjective evaluation for fuzzy group multicriteria decision making. European Journal of Operational Research, 194(2), 464-473. 
[314] Zadeh, L. (1965). Fuzzy sets. Information and Control, 8(3), 338-353.

[315] Zerros, C., \& Irani, K. (1977). Colored Petri nets: their properties and applications. Systems Engineering Lab. TR 107, Univ. of Michigan.

[316] Zoteva, D. \& Krawczak, M. (2017). Generalized Nets as a Tool for the Modelling of Data Mining Processes. A Survey. Issues in Intuitionistic Fuzzy Sets and Generalized Nets, 13, $1-60$. 